\title{
13-cis-Retinoic acid specific down-regulation of angiotensin type 1 receptor in rat liver epithelial and aortic smooth muscle cells
}

\author{
Russell Snyder and Thomas Thekkumkara \\ Department of Biomedical Sciences, Texas Tech University Health Sciences Center, 1300 South Coulter, Amarillo, Texas 79106, USA \\ (Correspondence should be addressed to T Thekkumkara; Email: thomas.thekkumkara@ttuhsc.edu)
}

\begin{abstract}
Transcriptional repression through cis- and trans-acting factors enabling an alternate approach to control angiotensin type 1 receptor (AT1 or AGTR1 as listed in the MGI database) expression has not been studied. In previous investigations, treatment with retinoic acid was found to be associated with enhanced insulin sensitivity. In our previous study, expression of AT1 was found to be inversely correlated with intracellular glucose concentrations. Therefore, we hypothesized that 13-cis-retinoic acid (13cRA), an antioxidant, enhances insulin-sensitive glucose-mediated downregulation of the AT1. In this study, we used continuously passaged rat liver epithelial cells. Our study shows that cells exposed to 13cRA specifically down-regulated the AT1 protein in a dose- and time-dependent manner, independently of any change in receptor affinity. Down-regulation of the AT1 expression leads to reduced Angll-mediated intracellular calcium release, a hallmark of receptor-mediated intracellular signaling. Similarly with receptor down-regulation, we observed a significant reduction in AT1 mRNA; however, the AT1 down-regulation was independent of insulin-sensitive glucose uptake and retinoic acid receptor activation (RAR/RXR). Treatment with 13cRA resulted in phosphorylation of p42/p44 MAP kinases in these cells. Subsequent studies using MEK inhibitor PD98059 prevented 13cRA-mediated AT1 down-regulation and restored Angll-mediated intracellular calcium response. Furthermore, 13cRA-mediated inhibitory effects on AT1 were validated in primary rat aortic smooth muscle cells. In summary, our results demonstrate for the first time that 13cRA has a glucose- and RAR/RXR-independent mechanism for transcriptional inhibition of AT1, suggesting its therapeutic potential in systems in which AT1 expression is deregulated in insulin-sensitive and -insensitive tissues.
\end{abstract}

Journal of Molecular Endocrinology (2012) 48, 99-114

\section{Introduction}

Angiotensin II (AngII) through the angiotensin type 1 receptor (AT1 or AGTR1 as listed in the MGI database) is a powerful vasoconstrictor and a key hormone controlling plasma volume and is thus highly interesting to the realm of hypertension research (Nickenig 2002, Wassmann \& Nickenig 2006). However, AngII is proving itself more ubiquitous in its importance to homeostasis outside its well-characterized hypertensive effects. It is a potent mitogenic/angiogenic stimulator (Escobar et al. 2004, Numaguchi \& Murohara 2009) and an inducer of growth factors relevant to hyperplasia and fibrosis development (Skultetyova et al. 2007), and responsive tissues outside the cardiovascular and renal systems are almost innumerable (Leung 2004). In particular, AngII has shown to play a part in the development of liver fibrosis and steatosis, and if one blocks AT1 with selective competitive antagonists, the exacerbation of these conditions by AngII ceases (Sookoian et al. 2005, Kim et al. 2008). Therefore, intervention against AngII's binding of AT1 is associated with not only a decrease in blood pressure but also a multisystemic effect.

Vitamin A, also known as retinol (an alcohol) or retinal (an aldehyde), is an essential dietary nutrient important for supporting a healthy immune system, maintaining normal eyesight and red blood cell production, and facilitating growth and development through gene transcriptional control (Blomhoff 1994). Retinoic acid, a metabolite of preformed vitamin A, exerts its function by binding to nuclear receptors (RXR and RAR) and forming complexes with specific sequences on promoter regions of target genes called retinoic acid response elements (Mark et al. 2006). Therefore, activity of a gene is dictated by recruitment of enhancer or repressor proteins such as nuclearcoactivator complex or nuclear-corepressor complex respectively. These are of course examples in a much larger panoply of effector molecules that may be recruited by an activated and DNA-bound nuclear receptor (Rosenfeld \& Glass 2001). The primary isomers of retinoic acid formed in vivo are all-transretinoic acid (atRA) and 9-cis-retinoic acid (9cRA); each 
binds separate retinoic acid receptor types, thus acting upon a select subset of genes (Chambon 1996). The 13-cis-retinoic acid (13cRA) is a synthetic form that may function similar to the other isoforms, although the exact mechanism of action is unclear; in other words, its activity may be due to spontaneous isomerization to atRA or a novel activity of its own (Kim et al. 1994, Levin 1995, Ganceviciene \& Zouboulis 2007). 13cRA has been used in the past as a dermatological preparation applied orally or topically to influence skin growth factors in such a way as to lower sebum secretion (Landthaler et al. 1980). As a result, its marketability to treat acne has overcast some of its more recent applications. For instance, it can be used as a monotherapy or in combination for the treatment of cutaneous T-cell lymphoma (Zhang \& Duvic 2003) and oral leukoplakia (Piattellia et al. 1999), and as a differentiating agent in myelodysplastic conditions (Siitonen et al. 2007). Though 13cRA has multiple applications and therapeutic targets, the cellular mechanisms and molecular targets are not understood.

Previously, we had reported that there is an inverse relationship between glucose levels and expression of the AT1 in proximal tubule epithelial cells (Thomas \& Thekkumkara 2004). Several studies have shown that the AngII-induced cellular response (i.e. hyperplasia) may be blocked by retinoic acid treatment (Wu et al. 1996, Wang et al. 2002, Lu et al. 2003). Indeed, retinoic acid has been recognized to be associated with renin-angiotensin system signaling (Choudhary et al. 2008a). From the perspective of these studies, one of the two possibilities is represented: either the members of the multicomponent signal transduction cascade mediated by stimulation of the AT1 are being blocked specifically by retinoic acid (i.e. ERK1/2, p38, and STAT-JAK) or the receptor is being down-regulated leading to impairment of all subsequent pathways. Furthermore, studies have indicated that retinoic acid can induce peroxisome proliferator-activated receptor $\gamma(\operatorname{PPAR} \gamma)$ and thus lead to an insulin-sensitized cell (Krskova-Tybitanclova et al. 2008, Macejova et al. 2009, Manolescu et al. 2010). We hypothesized that retinoic acid is capable of down-regulating the AT1 itself; if the AT1 is being down-regulated, it may be due to increased insulin sensitivity and increased intracellular glucose uptake. In this study, we used continuously passaged rat liver epithelial cells (WBs) sensitive to insulin-facilitated glucose transporters as a model system for studying the regulation of AT1 expression. We demonstrated that 13cRA is capable of down-regulating AT1 expression in these cells, which is independent of increased uptake of glucose or classical retinoic acid receptor (RAR/RXR) activation. Down-regulation of the AT1 correlated with reduced response to AngII-mediated intracellular calcium release in these cells. The 13cRA-mediated down-regulation we observed in these cells was determined to be due to MAP kinase activation. Furthermore, the observed effect was consistently reproduced in primary rat aortic smooth muscle cells (RASMC) in culture. To our knowledge, this is the first study elucidating the effects of 13cRA on AT1 expression and function.

\section{Materials and methods}

\section{Materials}

Continuously passaged rat liver epithelial cells (WB cells) were provided by Dr H Shelton Earp, University of North Carolina at Chapel Hill (Chapel Hill, NC, USA). Primary RASMC were from Lonza (Walkersville, MD, USA). Richter's improved minimal essential medium was obtained from Cellgro-Mediatech, Inc. (Manassas, VA, USA). Fetal bovine serum (FBS) was from EquitechBio, Inc. (Kerrville, TX, USA). Oligonucleotide primers and biotinated probes were obtained from Integrated DNA Technologies, Inc. (Coralville, IA, USA). PCR master mix was from Roche (Branchburg, NJ, USA). Losartan was provided by Merck Sharp and Dohme Research Laboratories (Rahway, NJ, USA). 13cRA, insulin, actinomycin $\mathrm{D}$, and gentamicin were from Sigma (St. Louis, MO, USA). DNA/RNA extraction reagents were from Ambion/ABI (Austin, TX, USA). $\left[{ }^{3} \mathrm{H}\right]$ AngII was from Amersham. Selective RAR and RXR antagonists BMS453 and HX531 were from Tocris Biosciences (Ellisville, MO, USA). $\left[{ }^{3} \mathrm{H}\right]_{\mathrm{D}}$-glucose was from Perkin-Elmer (Waltham, MA, USA). Fura-2 AM and PD98059 were from Calbiochem (La Jolla, CA, USA). AT1 antibody was from Santa Cruz Biotechnology (Santa Cruz, CA, USA) and phospho-MAP kinase antibody was from Cell Signaling (Danvers, MA, USA). Real-time PCR reagents and equipment were from Applied Biosystems (Carlsbad, CA, USA). Electrophoresis reagents were from Bio-Rad (Richmond, CA, USA), and all other chemicals and molecular biology grade agents were purchased from Fisher Scientific (Fairlawn, NJ, USA).

\section{Cell culture}

The WB cells were maintained in Richter's improved MEM supplemented with $10 \%$ FBS, $10 \mathrm{mM}$ glucose, $17 \cdot 8 \mathrm{mM}$ HEPES, $5 \cdot 4 \mu \mathrm{g} / \mathrm{ml}$ insulin, and $44 \cdot 6 \mu \mathrm{g} / \mathrm{ml}$ gentamicin at $37{ }^{\circ} \mathrm{C}$ in $5 \% \mathrm{CO}_{2}$ with $100 \%$ humidity. For the studies, cells were grown to $70-80 \%$ confluence and the medium was exchanged with treatment medium (Richter's improved MEM supplemented with 5\% FBS, $5 \mathrm{mM}$ glucose, $17 \cdot 8 \mathrm{mM}$ HEPES, $5 \cdot 4 \mu \mathrm{g} / \mathrm{ml}$ insulin, and $44 \cdot 6 \mu \mathrm{g} / \mathrm{ml}$ gentamicin). After $24 \mathrm{~h}$, cells were exposed to treatment medium containing 13cRA for indicated concentrations and times. For primary culture of 
RASMC, the cells were maintained in Richter's improved MEM supplemented with $20 \%$ FBS, $10 \mathrm{mM}$ glucose, $17 \cdot 8 \mathrm{mM}$ HEPES, $5.4 \mu \mathrm{g} / \mathrm{ml}$ insulin, and $44.6 \mu \mathrm{g} / \mathrm{ml}$ gentamicin at $37^{\circ} \mathrm{C}$ in $5 \% \mathrm{CO}_{2}$ with $100 \%$ humidity. For the studies, cells were grown to $70-80 \%$ confluence and the medium was exchanged with treatment medium (identical to the WB treatment medium) and exposed to indicated agents for indicated times. The cells used in this study were from passages 3 to 5 .

\section{Angiotensin receptor binding studies}

Receptor binding studies were performed in triplicate on WB or primary RASMC before and after 13cRA exposure as described previously (Thekkumkara et al. 1995). Briefly, the cells were washed twice with PBS and incubated with $\left[{ }^{3} \mathrm{H}\right]$ AngII $(20 \mathrm{pM})$ at $22{ }^{\circ} \mathrm{C}$ in a binding buffer containing $50 \mathrm{mM}$ Tris- $\mathrm{HCl}(\mathrm{pH} \mathrm{7.5}), 120 \mathrm{mM}$

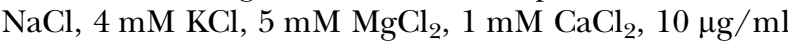
bacitracin, $2 \mathrm{mg} / \mathrm{ml}$ dextrose, and $2.5 \mathrm{mg} / \mathrm{ml}$ BSA. After 60 min incubation, the cells were washed with ice-cold PBS three times to remove free radioactivity. Cells were then lysed with $0 \cdot 1 \%$ Triton X-100 in PBS. The cells were scraped and transferred to counting vials and radioactivity was determined using a Beckman liquid scintillation counter. Specific $\left[{ }^{3} \mathrm{H}\right]$ AngII binding was defined as that portion of the total binding displaced by $1 \mu \mathrm{M}$ unlabeled AngII. At equilibrium, specific binding was more than $95 \%$ of the total binding. Protein concentrations were determined using the Bio-Rad protein assay system based on the Bradford method (Bradford 1976). Data were analyzed and nonlinear regression curves were obtained using the computer software GraphPad Prism (la Jolla, CA, USA); $K_{\mathrm{d}}$ and $B_{\max }$ were calculated as described previously (Swillens 1992).

\section{Western blot analysis}

Cells were lysed by sonification in lysis buffer containing $50 \mathrm{mM}$ HEPES, $1 \%$ Triton X-100, $50 \mathrm{mM} \mathrm{NaCl}, 50 \mathrm{mM}$ $\mathrm{NaF}, 10 \mathrm{mM}$ sodium pyrophosphate, $5 \mathrm{mM}$ EDTA, and one tablet per $10 \mathrm{ml}$ Mini-Complete Protease Inhibitor (Roche). Equal amounts of protein $(25 \mu \mathrm{g} /$ lane $)$ were resolved by SDS-PAGE and transferred onto a nitrocellulose filter (Millipore, Billerica, MA, USA). The filters were blocked with Tris-buffered saline (TBS) containing 5\% nonfat milk and incubated with monoclonal antibody against phospho-MAP kinase p42/p44, total MAP kinase p42/p44 (1:1000 dilution; Cell Signaling), or monoclonal antibody against actin (1:3000 dilution; Santa Cruz, USA). After washing three times with TBS containing $0.5 \%$ Tween-20, bound primary antibody was detected with antirabbit
HRP-conjugated goat IgG (1:5000 dilution; Santa Cruz Biotechnologies, Santa Cruz, CA, USA). Immunoreactive proteins were visualized using the chemiluminescent substrate kit from Pierce Biomedical (Thermo-Scientific Pierce, Rockford, IL, USA).

\section{Reverse transcriptase: dual PCR, real-time qPCR, and Southern blot analysis}

Cells were grown to $70-80 \%$ confluency and treated with or without $25 \mu \mathrm{M} \mathrm{13cRA}$ for $24 \mathrm{~h}$. Total RNA was isolated using the guanidium thiocyanate-phenol-chloroform method as described previously (Thekkumkara \& Linas 2003). Total RNA was quantified and $5 \mu \mathrm{g} /$ condition was processed for cDNA template conversion using MLV-RT. The reaction without reverse transcriptase served as a control for DNA contamination. The cDNA was then amplified with a dual-PCR primer set for $A T 1$ and $\beta$-actin mRNA (AT1 sense: 5'-TGATTCAGCTGGGCGTCATCCA- ${ }^{\prime}{ }^{\prime}, A T 1$ antisense: $5^{\prime}$-TTTCGTAGACAGGCTTGAGTGGG- $3^{\prime} ; \quad \beta$-actin sense: $5^{\prime}$-CGGAACCGCTCATTGCC-3', $\beta$-actin antisense: $5^{\prime}$-ACCCACACTGTGCCCA TCTA-3' ${ }^{\prime}$ ). The PCR was performed in a $50 \mu \mathrm{l}$ sample volume subjected to 30 cycles and the amplicons were analyzed on a $2 \%$ agarose ethidium bromide gel. Bands were visualized under u.v. to assure appropriate band density among $\beta$-actin controls and transferred to a nylon membrane using Southern capillary transfer as described previously (Brown 2001). The amplicon was then hybridized with biotinylated internal probes specific for both AT1 ( $5^{\prime}$-CTGACATCGTGGACACTGCCATG- $\left.3^{\prime}\right)$ and $\beta$-actin ( $5^{\prime}$-AGAGGGAAATCGTGGGTGACATT- $\left.3^{\prime}\right)$. The membranes were then washed and bands visualized using Chemiluminescent Nucleic Acid Detection Module according to the manufacturer's instructions (Thermo-Scientific). The intensity of the bands was captured by the Bio-Rad Versa Doc and quantified using Quantity One software. For real-time quantitative analysis of AT1 mRNA, two parallel PCRs, each containing $5 \mu \mathrm{g}$ total mRNA and either AT1- or $\beta$-actin-specific primers, were performed using 2X SYBR Green Master Mix (Applied Biosystems). Following the reaction, threshold cycles $\left(C_{\mathrm{t}}\right)$ were calculated for each sample for $A T 1$ and $\beta$-actin mRNA reactions, and quantitative concentrations were calculated using $\Delta \Delta C_{\mathrm{t}}$ calculations described by PerkinElmer Applied Biosystems. For the mRNA stability studies, cells were preincubated with $1 \mu \mathrm{g} / \mathrm{ml}$ actinomycin D for $15 \mathrm{~min}$ and then treated with or without 13cRA for indicated times. Total RNA was isolated using the method as described above. The densitometric data were further analyzed by linear regression using GraphPad Prism software to determine the half-life of the $A T 1$ mRNA. 


\section{$\left[{ }^{3} \mathrm{H}\right] \mathrm{Glucose}$ uptake assay}

Cells were grown to $70-80 \%$ confluence in 12-well plates. Growth media were exchanged for media supplemented with or without insulin and in the presence or absence of 13cRA, leaving a total of four treatment groups. At the end of $24 \mathrm{~h}$, cells were washed twice with warm PBS followed by replacement with growth medium containing $1 \%$ FBS and no glucose. After $15 \mathrm{~min}$, the media were exchanged for growth media containing $1 \% \mathrm{FBS}$ and $5 \mathrm{mM}$ glucose. To each well, $100 \mathrm{nCi}\left[{ }^{3} \mathrm{H}\right] \mathrm{D}$-glucose was added, and the cells were incubated for $20 \mathrm{~min}$ at $37^{\circ} \mathrm{C}$. The medium was aspirated, and the cells were washed three times with chilled PBS. The cells were then lysed with a lysis buffer containing 1\% SDS and $200 \mathrm{mM} \mathrm{NaOH}$. The lysates were collected and the radioactivity was determined in a liquid scintillation counter. Specific activity was correlated with picomoles of glucose uptake per milligram of protein per unit time.

\section{Immunofluorescent microscopy}

Cells were seeded and grown in chamber slides (NalgeNunc International, Rochester, NY, USA) and then exposed to 13cRA for $24 \mathrm{~h}$. At the end of $24 \mathrm{~h}$, cells were washed once with ice-cold PBS and fixed for $20 \mathrm{~min}$ in $4 \%$ paraformaldehyde. Cells were then blocked in $5 \%$ goat serum for $1 \mathrm{~h}$ and incubated in primary antibody (dilution 1:1000; Santa Cruz) directed against rat AT1 overnight at $4{ }^{\circ} \mathrm{C}$. They were washed five times with ice-cold PBS and incubated at room temperature for $2 \mathrm{~h}$ with Alexa-Fluor 488 conjugated secondary antibody (dilution 1:3000; Invitrogen). Washed cells were stained with $10 \mathrm{nM} 4^{\prime}$,6-diamidino-2-phenylindole (DAPI) for $5 \mathrm{~min}$. After a final wash, ProLong Gold AntiFade from Invitrogen was applied and placed under coverslips. Slides were held at $4^{\circ} \mathrm{C}$ for $48 \mathrm{~h}$. Image capture was performed at $22^{\circ} \mathrm{C}$ using an Olympus IX-81 microscope equipped with an Olympus U-CMAD3 camera under a PlanApo $60 \times / 1,40$ oil immersion objective. Images were analyzed using Slidebook software.

\section{Measurement of cytosolic free $\mathrm{Ca}^{2+}$ concentration}

WB cells grown to 70-80\% confluence in $35 \mathrm{~mm}$ optical bottom plates (MatTek \#P35G-0-10-C, Ashland, MA, USA) and AngII-induced changes in intracellular calcium were monitored using the microspectrofluorometry method as described previously (Grynkiewicz et al. 1985). Briefly, cells were loaded with $1 \mu \mathrm{M}$ fura2AM in HBSS for 20 min. The cells were washed twice with HBSS and changes in intracellular $\mathrm{Ca}^{2+}$ were measured. The microscope's emission wavelength was set at $510 \mathrm{~nm}$ and the excitation wavelengths at 340 and
$380 \mathrm{~nm}$. Image capture was performed at $22{ }^{\circ} \mathrm{C}$ using an Olympus IX-81 microscope equipped with an Olympus U-CMAD3 camera under a PlanApo $60 \times / 1,40$ oil immersion objective. Excitation was monitored by a high-speed wavelength-switching device, recorded with a CCD camera. Images were collected and analyzed using Slidebook image analysis software. Alternatively, we quantified the AngII-induced increase in intracellular calcium by the fluorescent imaging plate reader (FLIPR) method as described in Grynkiewicz et al. (1985). In short, $70-80 \%$ confluent cells in six-well plates were loaded with $1 \mu \mathrm{M}$ fura-2AM in $1 \mathrm{ml}$ Dulbecco's PBS (DPBS) for $1 \mathrm{~h}$ at $37^{\circ} \mathrm{C}$. The cells were then washed once with warmed DPBS and twice with FLIPR buffer (145 mM NaCl, $2 \cdot 5 \mathrm{mM} \mathrm{KCl}, 10 \mathrm{mM}$ HEPES, $10 \mathrm{mM}$ glucose, $1.2 \mathrm{mM} \mathrm{MgCl}_{2}$, and $1.5 \mathrm{mM}$ $\mathrm{CaCl}_{2}$ ). They were then analyzed in $900 \mu \mathrm{l}$ FLIPR buffer on the BioTek SynergyMx fluorescent plate reader for baseline readings for $2 \mathrm{~min}$, and AngII was added to a final concentration of $1 \mu \mathrm{M}$ for an additional $4 \mathrm{~min}$. At the end of each experiment, the maximum emissions for $\mathrm{Ca}^{2+}$-bound fura-2 and free fura- 2 were obtained by sequential addition of $20 \mu \mathrm{l}$ of $15 \mathrm{mM}$ digitonin and $20 \mu \mathrm{l}$ of $300 \mathrm{mM}$ EGTA. Changes in nanomolar concentrations of intracellular calcium were calculated using the formula:

$\Delta\left[\mathrm{Ca}^{2+}\right]=\left(\begin{array}{l}K_{\mathrm{d}}\left(F-F_{\min }\right) \\ \left(F_{\max }-F\right)\end{array}\right)-\left(\begin{array}{l}K_{\mathrm{d}}\left(F_{\mathrm{x}}-F_{\min }\right) \\ \left(F_{\max }-F_{\mathrm{x}}\right)\end{array}\right)$

$K_{\mathrm{d}}$ in this equation is predetermined at $224 \mathrm{nM}$. $F$ corresponds to the fluorescence reading after AngII exposure, while $F_{\mathrm{x}}$ corresponds to the fluorescence reading just before AngII application. $F_{\min }$ is the minimal fluorescence detected after addition of EGTA. $F_{\max }$ is the maximum fluorescence detected after addition of digitonin.

\section{Statistical analysis}

Results were presented as mean \pm s.E.M. and the value of $P<0.05$ was considered statistically significant. Values were normalized to milligrams of protein determined by Bio-Rad DC protein assay system based on the Bradford method (Bradford 1976). Data were analyzed using the GraphPad Prism software, and the binding constants were determined as described previously (Swillens 1992).

\section{Results}

\section{3cRA reduces AT1 density}

In this study, to determine the effects of 13cRA on AT1 expression, we used a continuously passaged rat liver 
epithelial cell natively expressing the AT1. This cell line was originally isolated by Dr Grisham and coworkers in 1984 and is characterized as a normal adult rat liver epithelial diploid continuously passaged cell line (Tsao et al. 1984). This cell line has been extensively used by Dr Earp and coworkers, as well as other investigators, to delineate AngII-mediated AT1 cell signaling and function (Tsao et al. 1986, McCune \& Earp 1989, Huckle et al. 1990, 1992, Earp et al. 1995, Bokkala \& Joseph 1997, Li \& Earp 1997, Li et al. 1997, 1998, Bokkala et al. 2001). In this study, we used these cells up to passage 26 at which point there were no changes to the cell's phenotype (Huckle et al. 1990). Receptor binding studies have shown that tritiated AngII in the presence of the AT1 antagonist losartan displaces $88 \cdot 89 \pm 3 \cdot 849 \% \quad(P<0 \cdot 0001, n=9)$ of the specific binding determined by cold AngII $10^{-6} \mathrm{M}$. However, when the cells were treated with the AT2Rspecific antagonist PD123319, there was no detectable displacement of AngII-specific binding (mean difference $-0 \cdot 6520 \pm 6 \cdot 126 \%, P=0 \cdot 9168, n=9$ ), indicating that these cells predominantly express the AT1 (Fig. 1A). Upon completion of 24-h treatment with $25 \mu \mathrm{M}$ 13cRA, there was a marked reduction in AT1 binding $(72 \cdot 56 \pm 5 \cdot 359 \%, P<0 \cdot 0001, n=9)$. However, upon full blockade of the AT1 with losartan in the 13cRA-treated cells, the remainder of the binding was equivalent with the control losartan-treated group. Additionally, there was no observed effect on the AT2R blockade group, when treated with 13cRA (mean difference $2 \cdot 726 \pm 2.922 \%, P=0 \cdot 3647, n=9$ ). This suggests that the observed reduction in AngII binding by 13cRA is specifically reducing the binding of AngII to the AT1 (Fig. 1A). To determine the specificity of this effect, we performed dose-response and time course studies. The dose-response study from 1 to $150 \mu \mathrm{M}$ shows a dose-dependent inhibition (Fig. 1B). For our future studies, we chose $25 \mu \mathrm{M}$ concentration for $24 \mathrm{~h}$ as it reliably showed $53 \cdot 0 \pm 6.5 \%(P<0 \cdot 0001)$ down-regulation with no cytotoxicity (determined by Hoescht staining, data not shown). Furthermore, the study using $25 \mu \mathrm{M}$ concentration shows a time-dependent effect up to $24 \mathrm{~h}$ (reduction of $43 \cdot 49 \pm 3 \cdot 814 \%$, $P<0.0001$ at 24 h; Fig. 1C). The above studies indicate that 13cRA is capable of reducing AngII binding specifically to the AT1 in a dose- and time-dependent manner.

However, the binding studies cannot fully rule out the change in receptor density because of the possibility that AngII binding to the receptor can be altered due to changes in the receptor affinity. Therefore, we performed competition binding studies to determine the affinity of the receptor in untreated cells and 13cRA-treated cells (Fig. 2). Calculated $K_{\mathrm{d}}$ in untreated cells was $3 \cdot 28 \pm 0 \cdot 66 \mathrm{nM}$. These receptors are in the high-affinity state, which is consistent with the
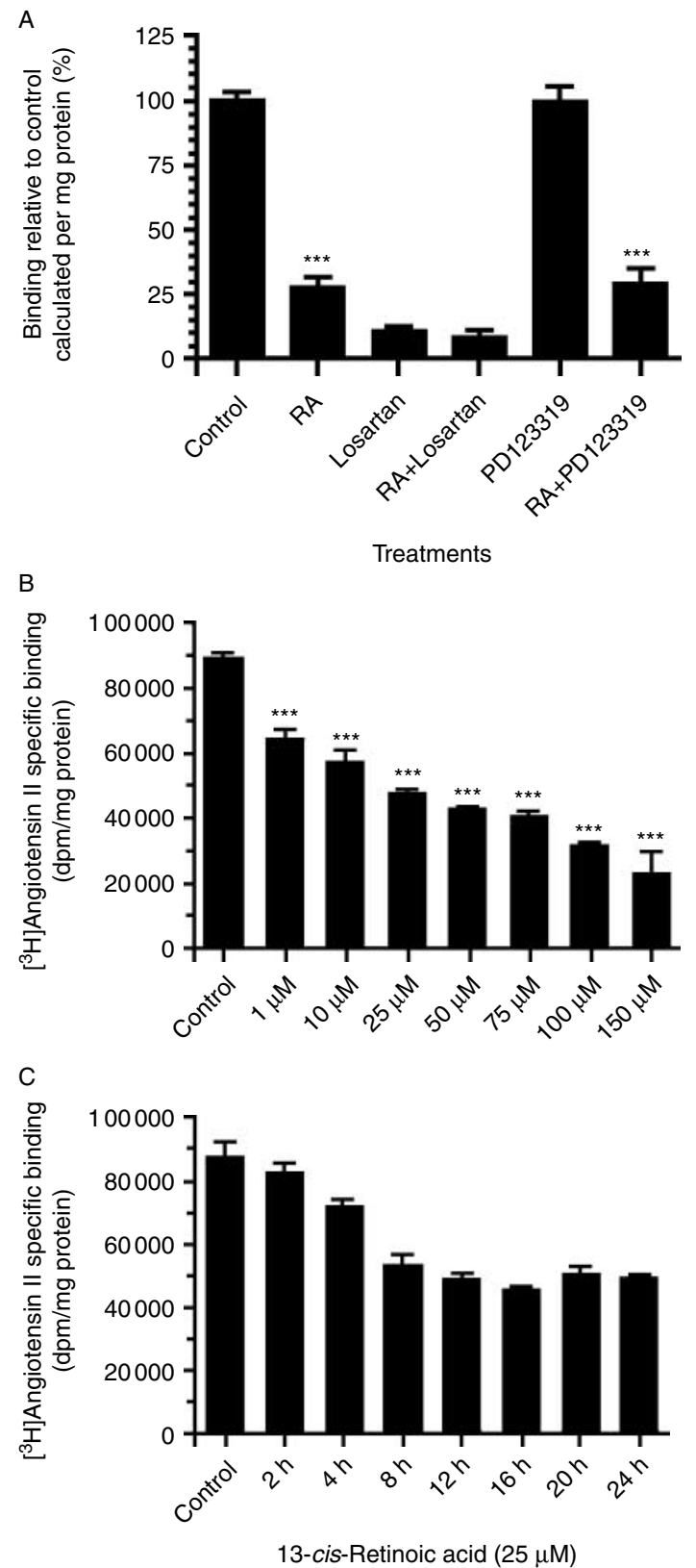

Figure 1 (A) 13cRA inhibits AT1-specific binding in WB cells. Radioligand binding assay after 24-h treatment with $25 \mu \mathrm{M} 13 \mathrm{cRA}$ (RA) and either losartan (Los) or PD123319 blockade. Cells were exposed to 13cRA $(25 \mu \mathrm{M})$ for $24 \mathrm{~h}$ and $\left[{ }^{3} \mathrm{H}\right]$ Angll binding was measured in the presence or absence of AT1 blocker losartan or AT2R blocker PD123319 $(n=9)$. (B) 13cRA-mediated AT1 inhibitory effect is dose dependent. Radioligand binding assay after variable concentrations $(1-150 \mu \mathrm{M})$ of 13cRA treatment for 24 h. $13 \mathrm{cRA}$ demonstrates $\mathrm{IC}_{50}$ at $25 \mu \mathrm{M}(n=9)$. (C) 13cRAmediated AT1 inhibitory effect is time dependent. Radioligand binding assay after exposure to $25 \mu \mathrm{M} 13 \mathrm{cRA}$ for variable treatment times as indicated. 13cRA inhibits AT1 binding $\geq 45 \%$ within $8 \mathrm{~h}$ and remains inhibited for the remainder of time-points $(n=9)$. Data are expressed as mean \pm S.E.M. ${ }^{* \star \star} P<0.0001$ vs untreated control. 

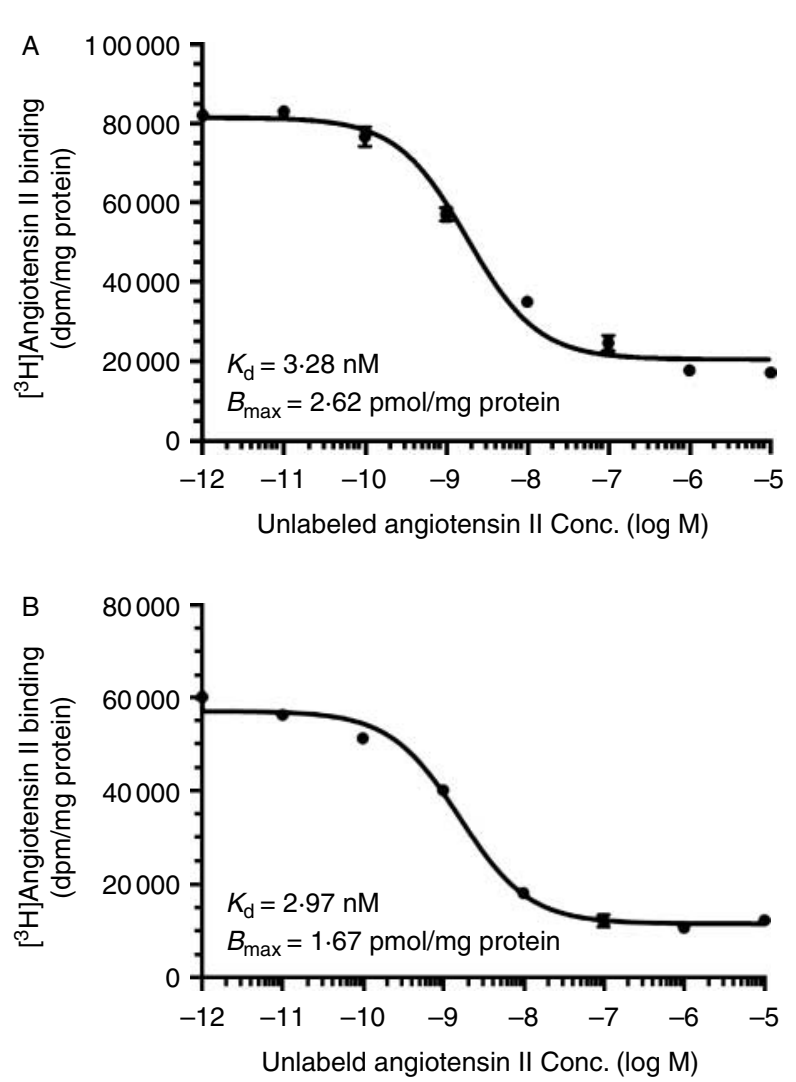

Figure 2 Competition binding studies reveal no change in receptor affinity after 13cRA treatment. Radioligand binding competition studies performed on untreated cells $(A)$ and cells treated with $25 \mu \mathrm{M}$ 13cRA for $24 \mathrm{~h}(\mathrm{~B})$. Nonlinear least squares regression analysis gave a $K_{\mathrm{d}}$ of $3.28 \mathrm{nM}$ for receptors in cells exposed to normal medium and a $K_{\mathrm{d}}$ of $2.97 \mathrm{nM}$ for receptors in cells exposed to 13cRA $(n=9)$.

previous literature. The 13cRA-treated cells' $K_{\mathrm{d}}$ was $2 \cdot 97 \pm 0.82 \mathrm{nM}$, suggesting that there is no apparent change in the $K_{\mathrm{d}}$ after 13cRA treatment. However, the maximum binding was reduced in 13cRA-treated cells $35 \cdot 6 \pm 3 \cdot 1 \%, P<0 \cdot 0001$. These findings suggest that the observed reduction in AngII binding is due to the reduction of cell surface receptors expressed in the plasma membrane.

In order to validate the reduction in surface expression, immunofluorescent studies were performed. Using a rabbit polyclonal antibody raised against the N-terminus of the AT1 (Santa-Cruz, SC1173 ) and later probed with an antirabbit Alexa-Fluor 488 conjugated secondary antibody (Invitrogen, A11034), the results show significant cell surface expression in the untreated cells compared with 13cRA-treated cells (Fig. 3). There is distinct staining at the plasma membrane well separated from the bluestained nuclei, providing further confirmation that the receptor density is indeed being reduced as indicated by $\left[{ }^{3} \mathrm{H}\right]$ AngII binding assays.

\section{AT1-mediated intracellular signaling reduced after 13cRA treatment}

In order to determine whether the apparent reduction in receptor expression on cell surface may translate into effective disruption of AngII-mediated cellular signaling, we conducted fluorescent calcium imaging studies. These analyses were conducted by both fluorescent imaging and an ELISA/FLIPR quantitation method. The results from the fluorescent image indicate that the maximum level of AngII-induced $\mathrm{Ca}^{2+}$ released in untreated cells was considerably higher, based on an intensity of $510 \mathrm{~nm}$ wavelength, than that in cells after treatment with $25 \mu \mathrm{M}$ 13cRA for $24 \mathrm{~h}$ (Fig. $4 \mathrm{~A}$ ). The ELISA/FLIPR assay using the algorithm shown in the Materials and methods section yielded a mobilized $\mathrm{Ca}^{2+}$ concentration of $554 \pm 56 \cdot 62 \mathrm{nM}$ in the untreated cells, while the 13cRA-treated cells yielded a mobilized $\mathrm{Ca}^{2+}$ concentration of $159 \pm 5 \cdot 21 \mathrm{nM}$ (a reduction of $71 \cdot 24 \pm 10 \cdot 26 \%, P=0 \cdot 0023$; Fig. $4 \mathrm{~B}$ ). The observed reduction in ELISA readings was consistent with our findings in fluorescence imaging for individual cell response. We performed an additional study to confirm the variable responsiveness at increasing doses of AngII to confirm the validity of using $10^{-6} \mathrm{M}$ AngII for eliciting a $\mathrm{Ca}^{2+}$ release (Fig. 4C). The results of the study indicated that the effect is dose dependent in cells in the presence or absence of 13cRA and was maximally stimulated by $10^{-7} \mathrm{M}$ AngII, with an equivalent response at $10^{-6} \mathrm{M}$ AngII (mean difference between control groups, $2 \cdot 571 \pm 14 \cdot 29 \% \quad(P=0 \cdot 8598, n=8)$, mean difference between treated groups, 1.410 $\pm 9 \cdot 320 \%(P=0 \cdot 8819, n=3))$. In summary, studies performed so far show a significant reduction in the expression of AT1 on the cell surface with no change in receptor affinity and a coinciding reduction in receptormediated cellular signaling.

\section{3cRA down-regulates AT1 mRNA expression}

We extended our studies to further investigate the expression of AT1 mRNA. We performed real-time qPCR calculating AT1 mRNA expression quantitatively to $\beta$-actin mRNA concentration. In Fig. 5A, the ethidium bromide-stained gel image shows specificity of the primers used and the purity of the RNA. The purpose of this image is to demonstrate successful PCR amplification with given primers with no DNA contamination. For results of the qPCR, see Fig. 5B. Our findings show that after exposure to $25 \mu \mathrm{M} 13 \mathrm{cRA}$ for $24 \mathrm{~h}$, there is a reduction of $54.37 \% \pm 10.45$ $(P=0.0065, n=3)$ in the level of AT1 mRNA compared with untreated cells (Fig. 5B). To determine whether this reduction was due to transcriptional repression, we estimated 13cRA-mediated changes in AT1 mRNA halflife in the presence of a transcriptional inhibitor, 

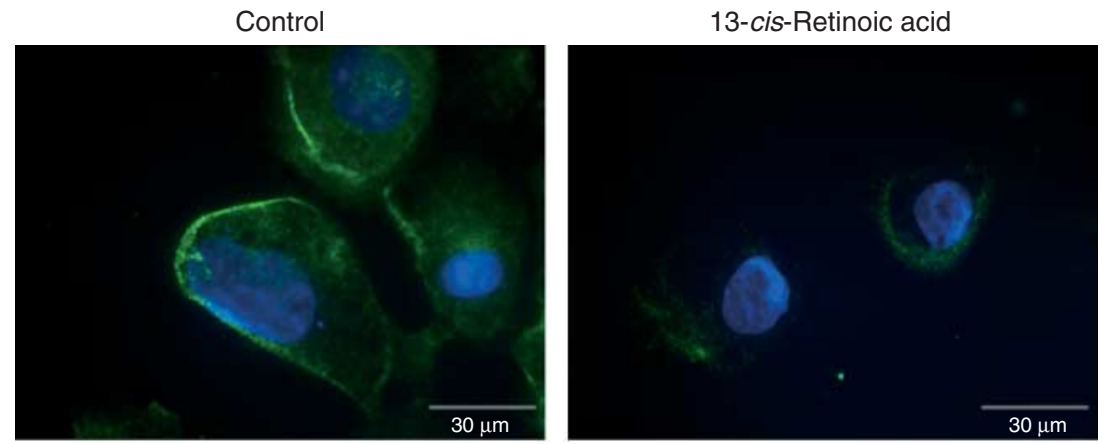

Figure 3 Immunofluorescent study shows the AT1 down-regulated in cells exposed to 13cRA. Immunofluorescent staining using primary rabbit anti-AT1 IgG followed by secondary antirabbit IgG conjugated with Alexa Fluor 488. Nuclei stained with $4^{\prime}, 6-$ diamidino-2-phenylindole (DAPI). (Left) Native AT1 in WB cells with no 13cRA exposure. (Right) AT1 expression after treatment with $25 \mu \mathrm{M} 13 \mathrm{cRA}$ for $24 \mathrm{~h}$.

actinomycin D. Cells were pretreated with $5 \mu \mathrm{M}$ actinomycin $\mathrm{D}$ for $20 \mathrm{~min}$ followed by exposure of $25 \mu \mathrm{M} 13 \mathrm{cRA}$ in treated groups. mRNA was extracted at 2-h intervals, and dual-PCR was carried out to calculate AT1 mRNA relative to $\beta$-actin density. The half-lives were calculated to be $7 \cdot 04 \pm 0 \cdot 179 \mathrm{~h}$ for untreated cells and $7 \cdot 13 \pm 0 \cdot 054 \mathrm{~h}$ for treated cells, demonstrating no significant difference, and further supporting that the reduction in $A T 1 \mathrm{mRNA}$ is mediated at the transcriptional level (Fig. 5C and D). Alternatively, we treated the cells with actinomycin $\mathrm{D}$ following a 16 -h preincubation in 13cRA-treated groups. The data were consistent with our findings from the previous actinomycin D study (data not shown). These studies indicate that 13cRA causes a significant reduction in the expression of $A T 1$ mRNA without affecting the rate of mRNA degradation, suggesting that there is 13cRA-mediated transcriptional repression leading to down-regulation of AT1 protein.

\section{3cRA down-regulates AT1 expression through MAP kinase p42/p44 activation}

In order to establish a mechanism for the transcriptional down-regulation of AT1 transcription by 13cRA, we performed studies in which we selectively inhibited retinoic acid receptors, RAR and RXR, with the specific antagonists BMS453 $(250 \mu \mathrm{M})$ and HX531 $(50 \mu \mathrm{M})$ respectively (Fig. 6). The results of these studies demonstrate that blockade of either receptor has no effect on 13cRA-mediated down-regulation of AngII binding, and thus AT1 expression (mean reduction in respective controls of $59 \cdot 11 \pm 6 \cdot 450 \%,(P<0 \cdot 0001$, $n=3)$ without RAR/RXR antagonism, $83 \cdot 01 \pm 4 \cdot 914 \%$ $(P<0 \cdot 0001, n=3)$ with RAR antagonism, and 66.78 $\pm 5 \cdot 890 \%(P<0 \cdot 0001, n=3)$ with RXR antagonism $)$. Had 13cRA mediated its effects through these receptors, we would have observed restoration of AngII binding; therefore, an alternate mechanism was investigated. Previous studies have shown that retinoic acid is capable of activating MAP kinase $\mathrm{p} 42 / \mathrm{p} 44$ involved in cellular differentiation (Yen et al. 1998). Therefore, we determined the role of 13cRA on MAP kinase $\mathrm{p} 42 / \mathrm{p} 44$ and AT1 down-regulation. Twenty-four hour treatment with $25 \mu \mathrm{M}$ 13cRA induced MAP kinase p42/p44 phosphorylation without a change in the total protein (Fig. 7A). This 13cRA-mediated phosphorylation was completely inhibited by MEK inhibitor PD98059. To determine the effect of MEK inhibition on the 13cRA-mediated down-regulation of mRNA expression and cell surface binding, studies were performed incorporating PD98059. Dual-PCR analysis shows the mRNA to be restored to control levels (mean difference increased $12 \cdot 33 \pm 4 \cdot 372 \%, P=0 \cdot 0765, n=3$ ) when treated with both PD98059 and 13cRA (Fig. 7B and $\mathrm{C}$ ). Under similar conditions, binding data showed that there was little to no effect by 13cRA on binding of $\left[{ }^{3} \mathrm{H}\right]$ AngII when MEK signaling was inhibited in the presence of PD98059 (reduction in binding from PD control $12 \cdot 7 \% \pm 6 \cdot 78, P=0 \cdot 089$; Fig. 7D). Similarly, FLIPR calcium imaging showed significant restoration of $\mathrm{Ca}^{2+}$ signaling by AngII stimulation when cotreated with PD98059 and 13cRA (PD group $\mathrm{Ca}^{2+}$ nanomolar mobilized $442 \pm 42 \cdot 6$ vs $\mathrm{PD}+13 \mathrm{cRA}$ group $\mathrm{Ca}^{2+}$ nanomolar mobilized $389 \pm 62 \cdot 0, P=0 \cdot 5140$; Fig. 8). Combining the results of receptor binding, mRNA, and calcium mobilization studied in the presence of the PD98059, our study shows that 13cRA-mediated downregulation is MAP kinase $\mathrm{p} 42 / \mathrm{p} 44$ dependent.

\section{3cRA-mediated down-regulation is glucose and insulin independent}

The WB cells used in this study are insulin sensitive, and intake of glucose is largely regulated through the facilitative transporters. Our study shows that glucose uptake was significantly reduced $(40 \cdot 33 \pm 9 \cdot 772 \%$, $P<0.0001$; Fig. 9A) in the absence of insulin compared with insulin-exposed cells. Glucose has been known to 
A
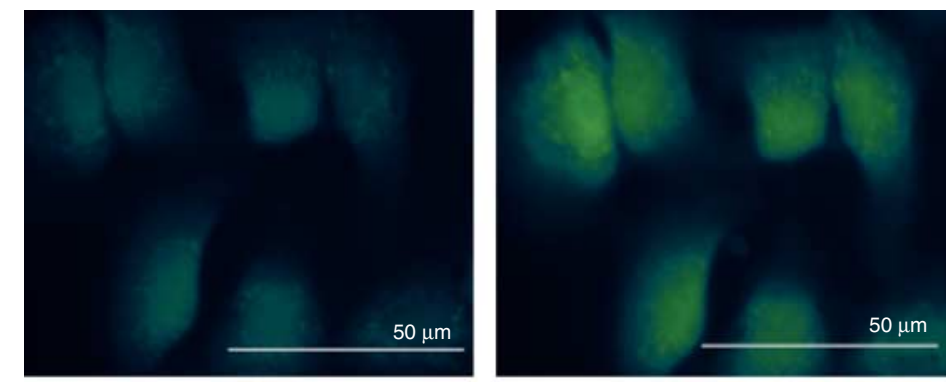

Control

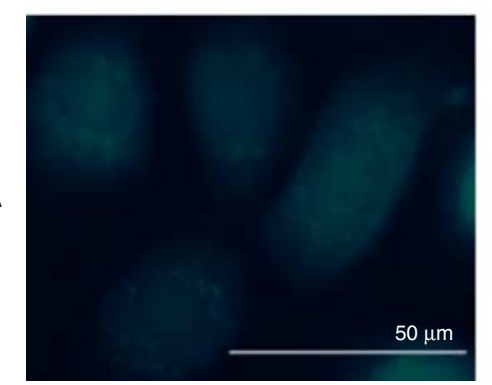

Angll (-)

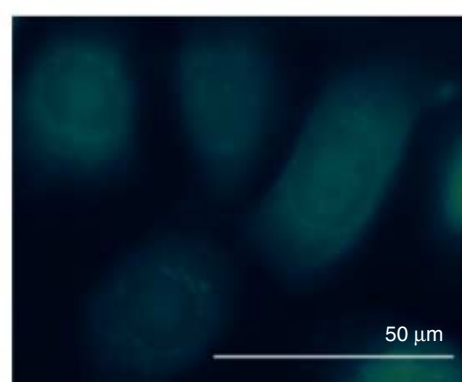

Angll (+)

B
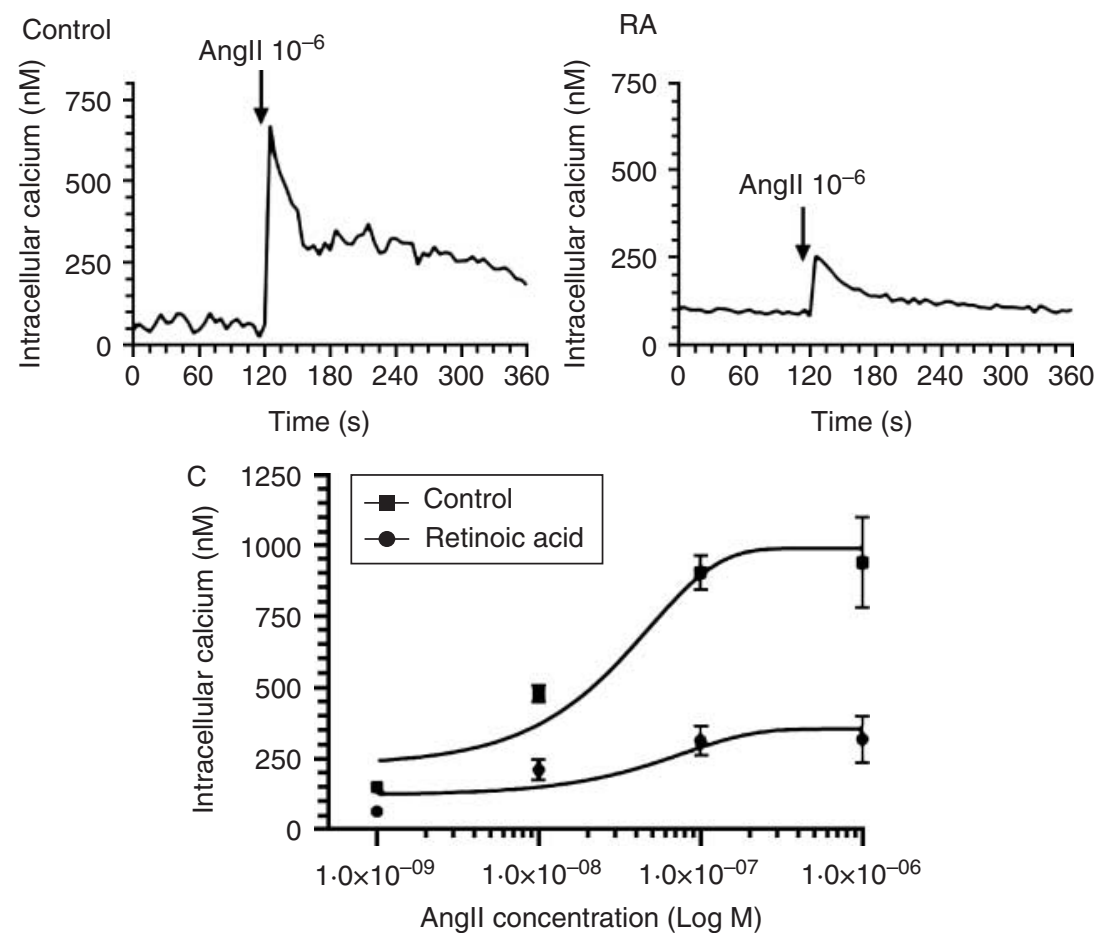

Figure 4 (A) Fluorescent imaging shows that $25 \mu \mathrm{M}$ 13cRA (RA) exposure for $24 \mathrm{~h}$ significantly inhibited Angll-mediated increase in intracellular $\mathrm{Ca}^{2+}$, a G-protein-coupled response. Transient free $\mathrm{Ca}^{2+}$ was measured with the $\mathrm{Ca}^{2+}$ indicator fura 2-AM using fluorescent imaging microscopy before and after Angll stimulation $\left(10^{-7} \mathrm{M}\right)$, with or without $13 \mathrm{cRA}$ treatment. $\mathrm{Ca}^{2+}$-bound fura 2-AM emits green fluorescence. (B) $\mathrm{Ca}^{2+}$ FLIPR assay shows a significant reduction in fluorescent emission after $25 \mu \mathrm{M}$ 13cRA exposure for $24 \mathrm{~h}$. Representative tracing of Angll-mediated transient increase in intracellular $\mathrm{Ca}^{2+}$ (left) without and with (right) 13cRA treatment. The tracings are representative of three separate experiments, an overall reduction of $71 \cdot 24 \pm 10 \cdot 26 \%$. (C) $\mathrm{Ca}^{2+}$ FLIPR assay performed with logarithmic dose of Angll to determine dose-response of calcium release in both treated and untreated WB cells. 
both activate MAP kinase $\mathrm{p} 42 / \mathrm{p} 44$ signaling and downregulate the receptor (Park et al. 2002, Thomas \& Thekkumkara 2004, Wang et al. 2010). Therefore, we examined whether glucose uptake was enhanced by 13cRA treatment. Glucose uptake assay shows that there was no significant change in the quantity of glucose uptake by 13cRA-treated cells compared with untreated cells (mean difference $3 \cdot 33 \pm 2 \cdot 88 \%, P=0 \cdot 3828, n=3$; Fig. 9A). The response was unaffected by the withdrawal of insulin (mean difference $5 \cdot 21 \pm 7 \cdot 88 \%, P=0 \cdot 5135$, $n=3$ ), indicating that 13cRA-mediated down-regulation is insulin independent. Furthermore, a binding study was performed to demonstrate the effect of insulin deprivation on 13cRA's down-regulatory function. While there was no effect among the 13cRA-treated groups (mean difference $1.49 \pm 8.81 \%, P=0.8669$ ), there was a significant increase in binding of $25 \cdot 8$ $\pm 6 \cdot 67 \%(P=0 \cdot 0008)$ when control cells were deprived of insulin (Fig. 9B), which is consistent but inversely related to our previous studies showing that increases in intracellular glucose concentrations result in decreased expression of the AT1. These studies show that 13cRA can mediate the down-regulation of AT1 independently of insulin-induced glucose uptake.

\section{3cRA-mediated effects on primary vascular smooth muscle cells}

To validate the WB cellular model of AT1 downregulation by 13cRA and thus create relevance to vasculature, we performed additional studies using primary RASMC (Fig. 10). The treatments were conducted using the same protocol established in the WB cell line, and the results show that 13cRA is capable of down-regulating AT1 in vascular smooth muscle cells in the rat. The study validated our previous findings that the down-regulation by $13 \mathrm{cRA}$ is AT1 specific and is mediated by MAP kinase p42/p44 activation. Upon treatment with $25 \mu \mathrm{M} 13 \mathrm{cRA}$, AngII binding in RASMC decreased by $58 \cdot 58 \pm 5 \cdot 185 \%(P<0 \cdot 0001, n=3)$. AT2R blockade by PD123319 had no effect in control cells (mean difference in control and PD123319-treated
A

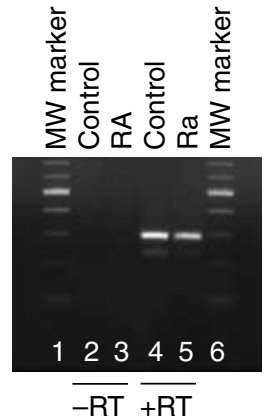

B

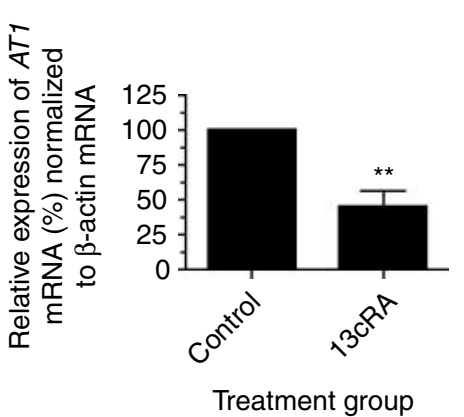

C

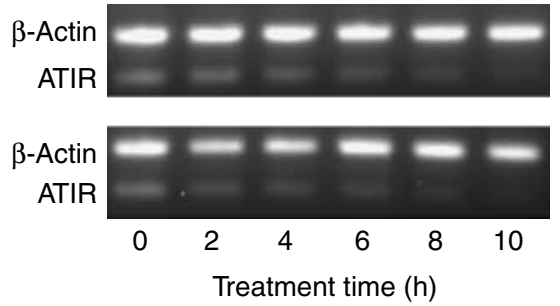

D

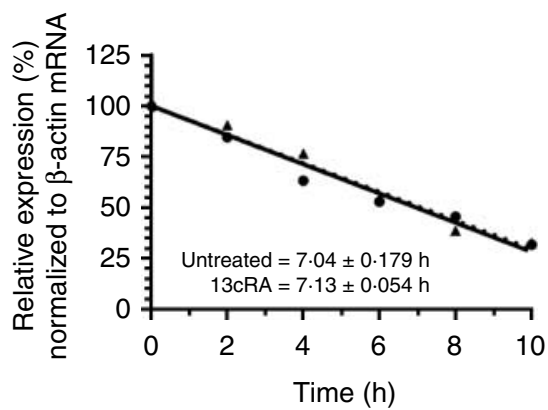

Figure 5 13cRA inhibits AT1 mRNA expression without changing mRNA stability. (A) Representative image of ethidium bromide gel of a dual-RT-PCR using AT1-/actinspecific primers to determine the specificity of the primers and purity of RNA preparation. Lanes 2 and 3 are PCRs lacking reverse transcriptase showing RNA purity. Two specific bands detected are at 289 and 206 bp for $\beta$-actin and AT1 mRNAs respectively. (B) AT1 expression was determined by real-time quantitative PCRs after normalization to $\beta$-actin and data are expressed as mean \pm S.E.M., $n=3 .{ }^{*} P<0.01$ compared with untreated control. (C) Representative dual-PCR ethidium bromide gel of actinomycin D exposed cells that were treated with (lower) or without (upper) $25 \mu \mathrm{M}$ 13cRA for indicated times. Bands were captured and quantified using Bio-Rad Quantity One software. AT1 bands are normalized to $\beta$-actin control. Bands detected are at 289 and $206 \mathrm{bp}$ for $\beta$-actin and AT1 mRNAs respectively. (D) mRNA half-lives were calculated using linear regression analysis $(n=3)$. 


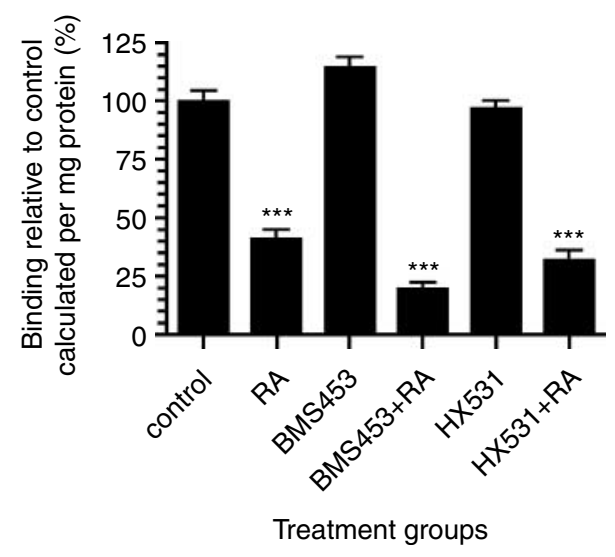

Figure 6 13cRA-mediated down-regulation of AT1 is independent of classical retinoic acid receptors. $\left[{ }^{3} \mathrm{H}\right]$ Angll binding downregulated despite RAR antagonism (250 $\mu \mathrm{M}$ BMS453) and RXR antagonism ( $50 \mu \mathrm{M} \mathrm{HX} 531)$. Radioligand binding assay was performed after 24-h exposure to $25 \mu \mathrm{M}$ 13cRA (RA) in the presence of respective agents indicated. Data are expressed as mean \pm S.E.M. ${ }^{\star \star \star} P<0.0001$ compared with control.

cells: $5 \cdot 382 \pm 6 \cdot 901 \%, P=0 \cdot 4476, n=3$ ), whereas losartan blockade significantly reduced total binding (mean difference in control and losartan-treated cells 90.68 $\pm 5 \cdot 192 \%, P<0 \cdot 0001, n=3)$. Losartan treatment caused no significant difference in 13cRA-treated cells compared with control losartan-treated cells $(P=0 \cdot 6496, n=3)$, though the down-regulation was consistent when comparing the control PD123319 control cells with the 13cRA- and PD12319-treated cells (down-regulation of $58 \cdot 20 \pm 6 \cdot 717 \%, P<0 \cdot 0001$, $n=3$ ). Finally, MEK inhibition and subsequently MAP kinase $\mathrm{p} 42 / \mathrm{p} 44$ inhibition resulted in restoration of binding in 13cRA-treated cells when compared with control, with no significant difference found between the two groups $(P=0 \cdot 1964, n=3)$. From these data, we confirmed that 13cRA down-regulates AT1 in RASMC through an MAP kinase p42/p44-dependent mechanism, and the WB cell model adequately portrays an effect that is not limited to tissue of hepatic origin.

\section{Discussion}

Numerous studies have shown that alterations in AT1 expression leading to altered regulation of downstream intracellular modulators dictate specific patterns in downstream effectors; however, the role of these intracellular modulators on AT1 transcription remains enigmatic (Bonde et al. 2010, Wakui et al. 2010, Ozawa et al. 2011). In this study, we examined the effect of 13cRA on the expression of AT1 in rat liver epithelial cells known to express the native protein. Our results show that 13cRA is capable of down-regulating AT1 cell surface expression by down-regulating its mRNA expression through an MAP kinase-mediated intracellular signaling that is insulin and glucose independent, as well as unrelated to classical retinoic acid receptor activation. The observed down-regulation is further correlated with intracellular signaling, such as intracellular calcium release, showing that the reduction in receptor density significantly disrupts AngII's ability to enact cellular response. The results specific to MAP kinase-dependent AT1 down-regulation were further confirmed in primary RASMC of vascular origin.

The blockade of AT1 stimulation has profound protective effects in pathologically affected tissues relative to AngII signaling (Baumann et al. 2010). In this particular study, preconditioning with AT1 blockers showed improved prognosis in spontaneous hypertensive heart failure rats; additionally, these rats showed reduced sensitivity and lower receptor expression in cardiac and aortic tissue. We may therefore suggest that reduced receptor expression as well as a reduction in the normal cellular response from either circulating or locally (tissue) derived AngII is beneficial in those at risk of overactive renin-angiotensin system consequences. For the liver, in particular, one may take account of AngII's potent activity. Studies have shown that blockade of AT1 in liver hepatocytes can attenuate fibrosis and steatosis (Ratziu \& Zelber-Sagi 2009). AngII is not the causative agent of these conditions, but it can influence the rapid progression to more irreversible states if left untreated by inducing oxidative stress in at-risk livers (Wei et al. 2008). In previous studies, ARBs and ACEIs have lowered the fibrosis index score of at-risk livers (Kim et al. 2008, Yoshiji et al. 2009). This was taken as evidence that one may slow the progression of steatosis and fibrosis by inhibiting the renin-angiotensin system of the liver or at least by preventing the AT1/ AngII interactions by ARB or ACEI therapy. Therefore, the observation in this liver cell model represents a finding of significant clinical importance.

Retinoids have been associated with improved responses to cardiac cellular injury. Vitamin A and its subsequent metabolism into retinoic acid have been proposed as a potential means for the regression of cardiac hypertrophy (Maier 2008). The atRA treatment prevents medial thickening of intrarenal and intramyocardial arteries in the SHR model (Lu et al. 2003), a model known to have up-regulated AT1 expression. Also, atRA supplementation has been shown to have protective effects on hypertrophic cardiomyocytes (Wang et al. 2002). AngII treatment in these cells resulted in increased protein production, as well as expression of a number of genes encouraging a hypertrophic phenotype. The atRA treatment significantly attenuated the expression of the hypertrophic effects after AngII exposure. In a related study involving an in vivo model, retinoic acid significantly attenuated ventricular remodeling after myocardial infarction, a 
A

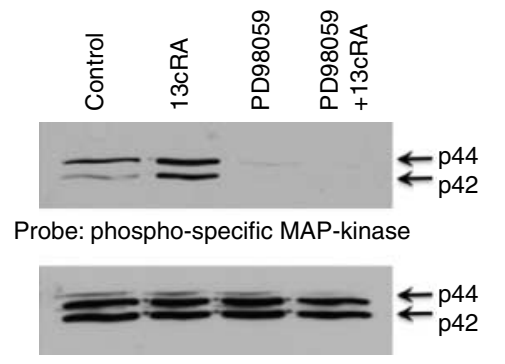

Probe: anti-MAP-kinase antibody

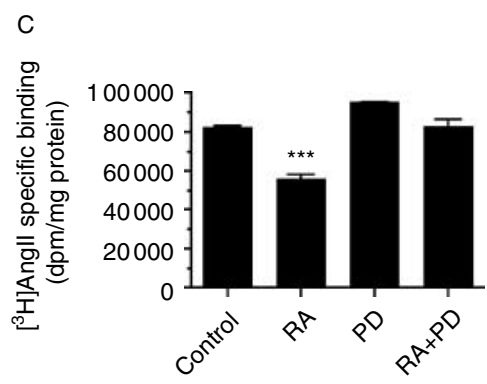

Treatment groups
B

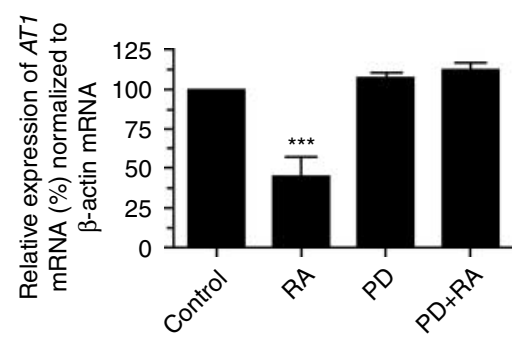

D

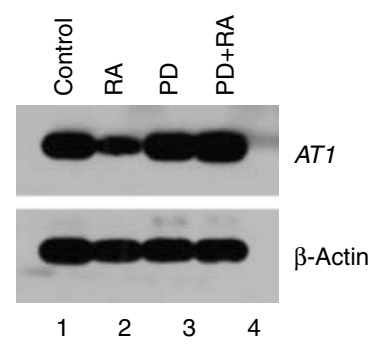

Figure 7 13cRA induces phosphorylation of MAP kinase p42/p44. (A) Total cell lysates were prepared from control, 13cRA-treated, the MEK inhibitor PD98059-treated, and 13cRA + PD98059-treated cells and immunoblotted with phospho-specific MAP kinase antibody (upper panel). Blot stripped and reprobed with anti-MAP kinase antibody to demonstrate equal loading (lower panel). A representative blot is shown $(n=3)$. (B) MEK inhibition restores AT1 mRNA expression in 13cRA-treated cells. Total RNA was prepared from control, 13cRA(RA)-treated, PD98059(PD)-treated, and 13cRA + PD98059-treated cells, as described in the Materials and methods section. Dual-PCR was performed followed by Southern blot analysis using internal probes specific for AT1 and $\beta$-actin mRNA. Intensity of the bands was captured and quantified using Bio-Rad Quantity One software. Quantitation of multiple analyses after AT1 expression was normalized to $\beta$ actin. Data are expressed as mean \pm S.E.M. ${ }^{\star \star \star} P<0.0001$ compared with control, $n=8$. (C) $\left[{ }^{3} \mathrm{H}\right]$ Angll binding is restored upon treatment with MEK inhibitor PD98059. Radioligand binding assay was performed after $25 \mu \mathrm{M} 13 \mathrm{cRA}$ (RA)-treated and -untreated cells for $24 \mathrm{~h}$ in the presence or absence of PD98059 (PD). Data are expressed as mean \pm S.E.M. ${ }^{* * *} P<0.0001$ compared with control. (D) Representative image of Southern blot.

process known to be enhanced by AngII stimulation (Paiva et al. 2005). It has been reported that MAP kinase phosphatases are up-regulated during atRA treatment (Palm-Leis et al. 2004). However, as with many of the recent analyses, MAP kinase activation as the characteristic marker for hypertrophic activation is contingent upon activation of AngII stimulation of the AT1. For example, a study showed that atRA treatment prevented cardiac remodeling in aortic-banded rats, a procedure that leads to increased AngII release (Choudhary et al. $2008 a$ ). This study indicated that if the rats are pretreated with atRA, MAP kinase $\mathrm{p} 42 / \mathrm{p} 44$ activation is prevented after aortic constriction. The finding is distinct from our observation, in which AngII is not a significant stimulator of MAP kinase $\mathrm{p} 42 / \mathrm{p} 44$. In other words, MAP kinase activation in our study is unrelated to AT1 activation by AngII and therefore may be considered as a distinct acute signaling mechanism.
Our study clearly demonstrates that MAP kinase p42/ p44 is essential to 13cRA-mediated down-regulation of AT1. This is contrary to much of the existing data involving AT1-induced MAP kinase activation. Furthermore, studies in the past have implicated retinoic acidmediated AngII/AT1 response disruption by downstream signaling pathways. The atRA treatment has been shown to up-regulate superoxide dismutase (Choudhary et al. 2008a). This was strongly supported from a previous observation that atRA treatment prevented AngII-induced oxidative stress in cardiomyocytes (Choudhary et al. 2008b). Therefore, the conclusion was that reduction of the oxidative stress by retinoic acid nullified the AngII-mediated cellular damage and inhibited cellular apoptosis. The atRA has been shown to directly affect the transcription of the $A T 1$ gene in vascular smooth muscle cells (Takeda et al. 2000), partially supporting our observation of the 

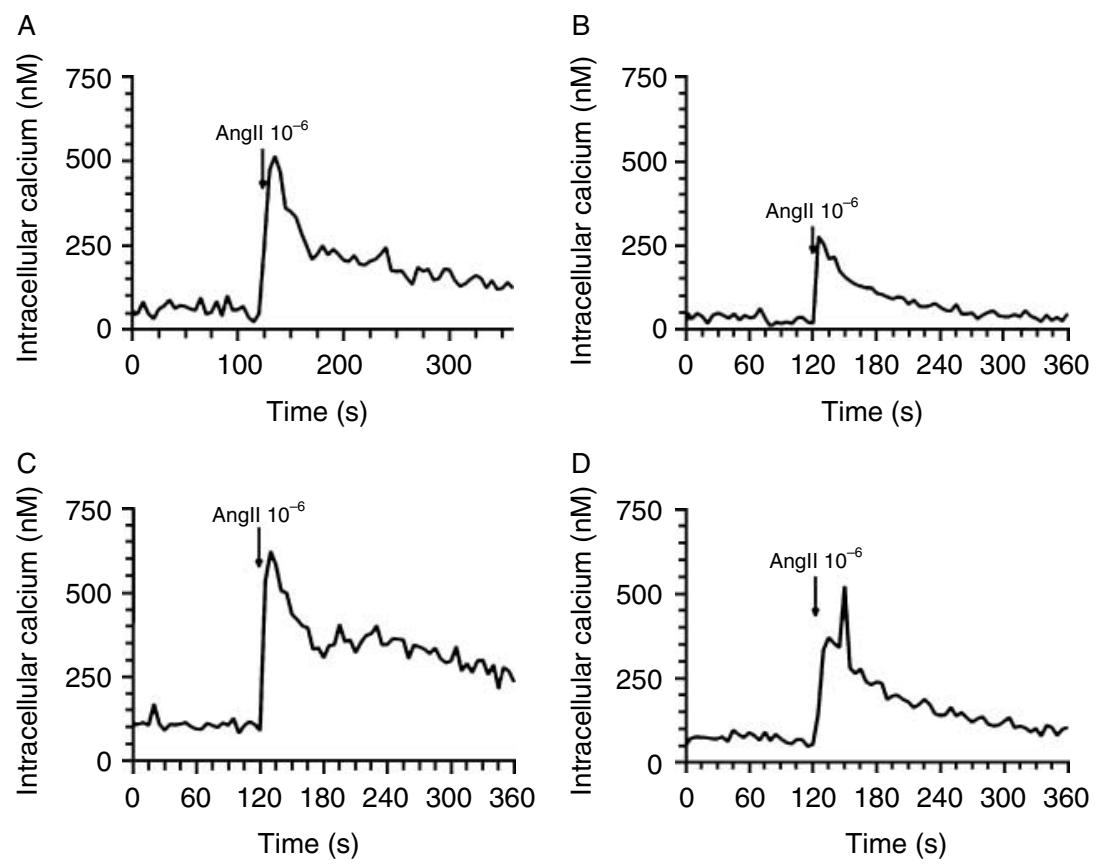

Figure $8 \mathrm{Ca}^{2+}$ FLIPR assay shows that MEK inhibitor PD98059 restores intracellular $\mathrm{Ca}^{2+}$ release in 13cRA-treated cells. Increase in intracellular $\mathrm{Ca}^{2+}$ was measured as described in the Materials and methods section. Representative tracings of transient increase in intracellular $\mathrm{Ca}^{2+}(\mathrm{A})$ in untreated control cells, (B) 13cRA-treated cells, (C) PD98059-treated cells, and (D) PD98059+13cRA-treated cells $(n=3)$.

transcriptional repression of AT1 by retinoic acids. However, the proposed mechanism in the current study and previous work involves different retinoids. Although the protein directly affecting the transcription of the AT1 was unknown from the Takeda et al. (2000) study, it was shown that RAR/RXR-dependent transcription of this unknown protein was critical for the down-regulatory effect by atRA. Interestingly, the researchers found that there was no detectable competition between RAR/RXR complexes and CBP, even though MAP kinase activation was shown to have an accelerative effect on the transcription of the AT1 gene due to CBP binding to the proximal region of the promoter in studies investigating PPAR $\gamma$ (Sugawara et al. 2003), suggesting a further level of complexity in the mechanism found in our study. However, the mechanism of action of 13cRA has been shown to be significantly different than either atRA or 9cRA, with potent inhibition of many of the retinoid and hydroxysteroid-mediated pathways (Gamble et al. 1999, Blaner 2001) and relatively weak transactivation compared with atRA and 9cRA (Mangelsdorf et al. 1994). In other words, 13cRA is not a potent activator of either RAR or RXR and should therefore probably be considered not as a comparable compound with other retinoic acids, but as a distinct compound with specific therapeutic applications. To further delineate our findings with the Takeda et al. (2000) study, we have shown that 13cRA-mediated down-regulation is related to an entirely unrelated mechanism, as RAR/RXR antagonism has no effect on 13cRA-mediated downregulation. 13cRA studies are not exclusively devoted to cardiac tissues. Indeed, there is one study that indicates 13cRA may impede AngII-induced hypertension by a direct effect on kidney tissues (Morath et al. 2009). Upon infusion of AngII, blood pressure was shown to be markedly elevated. However, with simultaneous treatment with 13cRA at both high and low doses, the increase in blood pressure by AngII was abolished. Additionally, renal damage in subtotally nephrectomized rats was markedly attenuated with concomitant treatment with 13cRA. Between our observations in two different cell types, the lowering of blood pressure in the Morath model as well as down-regulation of stimulation by AngII in the renal cortex, and observed antihypertrophic effects of retinoic acid (Wu et al. 1996, Wang et al. 2002, Lu et al. 2003), we believe that the effect of 13cRA on AT1 expression is not tissue specific.

There are numerous benefits in the choice of 13cRA as a therapeutic agent. Other retinoids are shown to have increased toxicity at high doses, particularly if consumed as preformed vitamin A (Mulholland \& Benford 2007). In fact, adverse effects may be observed with intake of retinol equivalents of only $1500 \mu \mathrm{g}$, which is less than twofold greater than the recommended 

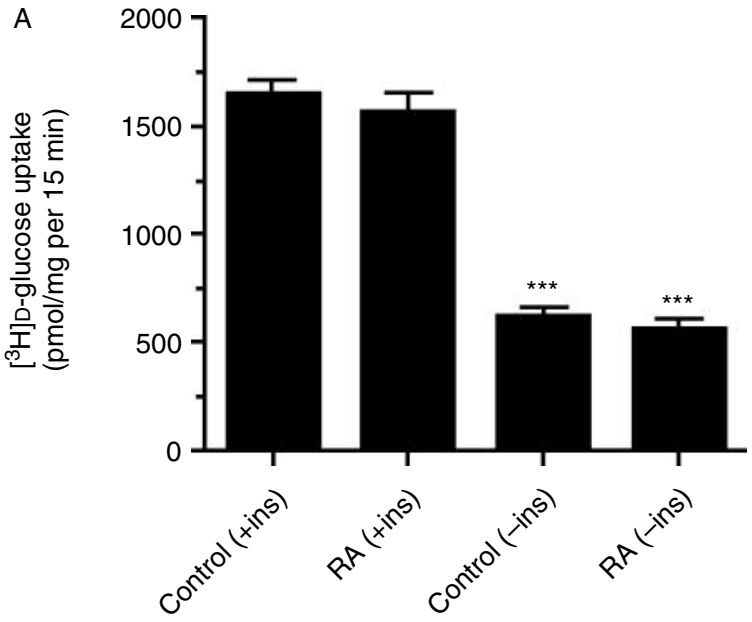

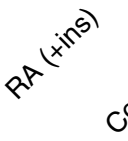

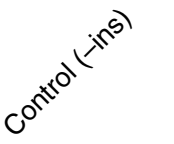

Treatment groups

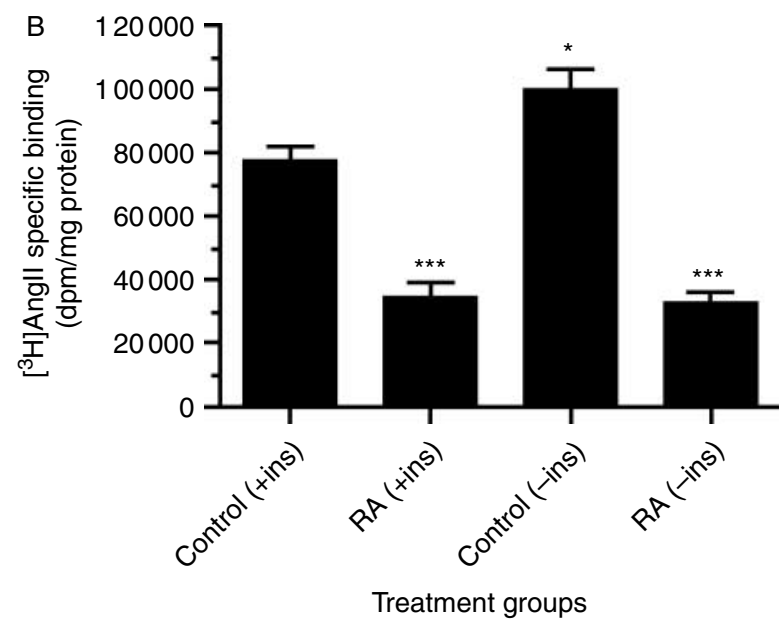

Figure 9 13cRA treatment caused no significant increase in glucose uptake; insulin withdrawal had no effect on 13cRAmediated down-regulation of AT1. (A) Cells were exposed to $25 \mu \mathrm{M}$ 13cRA (RA) for $24 \mathrm{~h}$ with or without insulin (Ins), followed by $15 \mathrm{~min}\left[{ }^{3} \mathrm{H}\right] \mathrm{D}$-glucose uptake assay. Data were calculated and expressed as picomoles of labeled glucose uptake per milligram protein per $15 \mathrm{~min}$. Untreated control with insulin compared with untreated control without insulin shows a reduction in glucose uptake of $40 \cdot 33 \pm 9 \cdot 772 \%$, ${ }^{\star \star *} P<0 \cdot 0001$. (B) Radioligand binding assay after 24-h exposure to $25 \mu \mathrm{M} \mathrm{13cRA}$ in the presence or absence of insulin. Data are expressed as mean \pm S.E.M. ${ }^{\star} P<0.05$ and ${ }^{* *} P<0.0001$ compared with untreated control $(n=3)$.

daily allowance. Liver toxicity is also a concern, as the liver acts as a reservoir for fat-soluble vitamins such as retinol. In contrast, 13cRA, aside from its potent teratogenic effects, carries very little danger as an acutely toxic agent. In one case, an overdose of $>900 \mathrm{mg}$ resulted in only minor and temporary dermatological and corneal manifestations with no permanent damage (Aubin et al. 1995). In other words, 13cRA has been referred to as the 'liver-sparing retinoid'. To add to its advantages, 13cRA does not induce cytochrome p450 enzymes (CYP1A 2C, 2E1, 3A, and 2D6) in the way that atRA does (Muindi et al. 2008), thus stabilizing its therapeutic window in chronic treatment. However, there are disadvantages in 13cRA application as a therapeutic agent. The principal concern for 13cRA therapy is its profound teratogenic effects (Ganceviciene \& Zouboulis 2007). Even low concentrations of 13cRA can cause significant birth defects in all stages of development, in particular, the suppression of cardiac development in the first trimester. AngII stimulation is critical in the development of cardiac tissue in the developing embryo; we may propose the mechanism by which the cardiosuppressive effect is mediated through the downregulation of AT1 in the embryonic tissue via 13cRA, leading to unresponsiveness in tissues to AngII. This proposed mechanism requires future studies for validation. In addition, delivery of retinoids is relatively inefficient as distribution is restricted by their high lipophilicity and limited absorption from oral administration. Consequently, the dose of a 13cRA regimen is relatively high (40-80 mg/day; Rigopoulos et al. 2010); there are promising innovations in drug delivery methods, such as cyclodextrins, to improve the plasma concentrations of smaller doses of 13cRA (Lin et al. 2007, Trichard et al. 2007).

In summary, our study provides compelling evidence of a down-regulatory role by 13cRA on the AT1; this role is apparently dependent on MAP kinase p42/p44 and dictates transcriptional repression. Further studies

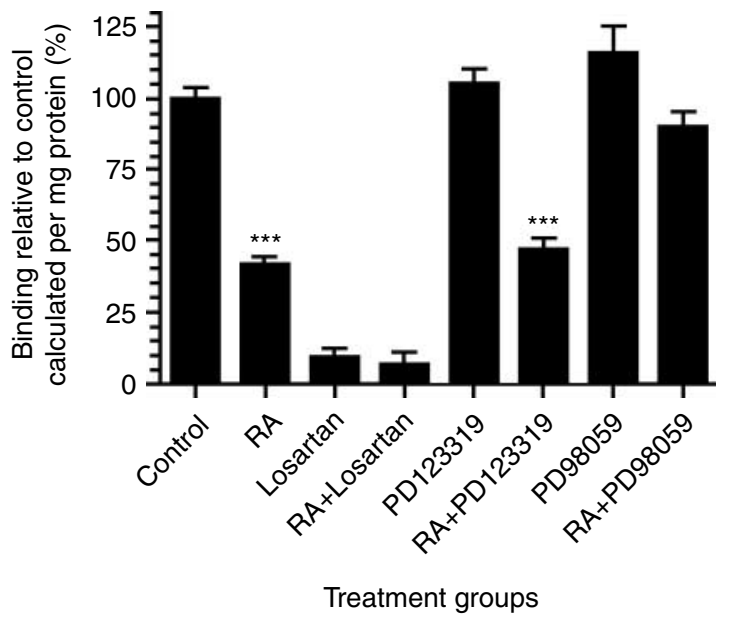

Figure 10 13cRA down-regulates AT1 in rat aortic smooth muscle cells (RASMC). 13cRA down-regulates $\left[{ }^{3} \mathrm{H}\right]$ Angll binding in a AT1-specific fashion. RASMC are not significant expressers of AT2R as indicated by PD123319 blockade $(10 \mu \mathrm{M})$. MEK inhibition and subsequent MAP kinase p42/p44 inhibition with the MEK inhibitor PD98059 (20 nM) restores $\left[{ }^{3} \mathrm{H}\right]$ Angll binding to control levels in the presence of 13cRA. Radioligand binding assay was performed after 24-h exposure to $25 \mu \mathrm{M}$ 13cRA (RA) with blockade of AT1/AT2R or MEK with the respective agents indicated. Data are expressed as mean \pm S.E.M. ${ }^{\star \star \star} P<0.0001$ compared with control, $n=9$. 
must be performed to elucidate the exact nature of this repressor mechanism. Sequence analysis shows a characteristic COUP-TFII response element in the AT1 promoter, which may show some importance with MAPK p42/p44 signaling (Aerbajinai et al. 2009). However, insulin and glucose were not involved in 13cRA down-regulation of AT1 as we had originally hypothesized. Moreover, mechanisms leading to 13cRAmediated activation of MAP kinase in our study also need further investigation. It is possible that binding of cytosolic-binding proteins, such as cellular retinoic acid binding protein II or fatty acid binding protein 5, has opposing effects through divergent signal transduction pathway activation (Schug et al. 2008), leading to differential signaling in a tissue-specific manner. Nevertheless, the results presented in this study favor the possible benefits of 13cRA as a suppressor of AT1 expression and function, resulting in potential multisystem protective effects.

\section{Declaration of interest}

The authors declare that there is no conflict of interest that could be perceived as prejudicing the impartiality of the research reported.

\section{Funding}

This study was supported in part by a research grant from the National Institute of Health (\#DK072140) and was associated with the awarding of a travel scholarship and best thematic poster award to $\mathrm{R} \mathrm{S}$ at Experimental Biology 2010 in Anaheim, California.

\section{Acknowledgements}

The authors would like to thank Ms Logan LaRue for editorial assistance.

\section{References}

Aerbajinai W, Zhu J, Kumkhaek C, Chin K \& Rodgers GP 2009 SCF induces gamma-globin gene expression by regulating downstream transcription factor COUP-TFII. Blood 114 187-194. (doi:10.1182/ blood-2008-07-170712)

Aubin S, Lorette G, Muller C \& Vaillant L 1995 Massive isotretinoin intoxication. Clinical and Experimental Dermatology 20 348-350. (doi:10.1111/j.1365-2230.1995.tb01341.x)

Baumann M, Sollinger D, Roos M, Lutz J \& Heemann U 2010 Prehypertensive preconditioning improves adult antihypertensive and cardioprotective treatment. Journal of Pharmacology and Experimental Therapeutics 332 1121-1126. (doi:10.1124/jpet.109. $161075)$

Blaner WS 2001 Cellular metabolism and actions of 13-cis-retinoic acid. Journal of the American Academy of Dermatology 45 S129-S135. (doi:10. $1067 /$ mjd.2001.113714)

Blomhoff R 1994 Transport and metabolism of vitamin A. Nutrition Reviews 52 S13-S23. (doi:10.1111/j.1753-4887.1994.tb01382.x)

Bokkala S \& Joseph SK 1997 Angiotensin II-induced down-regulation of inositol trisphosphate receptors in WB rat liver epithelial cells.
Evidence for involvement of the proteasome pathway. Journal of Biological Chemistry 272 12454-12461. (doi:10.1074/jbc.272.19. 12454)

Bokkala S, Reis HM, Rubin E \& Joseph SK 2001 Effect of angiotensin II and ethanol on the expression of connexin 43 in WB rat liver epithelial cells. Biochemical Journal 357 769-777. (doi:10.1042/02646021:3570769)

Bonde MM, Hansen JT, Sanni SJ, Haunsø S, Gammeltoft S, Lyngsø C \& Hansen JL 2010 Biased signaling of the angiotensin II type 1 receptor can be mediated through distinct mechanisms. PLOS ONE 5 e14135. (doi:10.1371/journal.pone.0014135)

Bradford MM 1976 A rapid and sensitive method for the quantitation of microgram quantities of protein utilizing the principle of protein-dye binding. Analytical Biochemistry 72 248-254. (doi:10. 1016/0003-2697(76) 90527-3)

Brown T 2001 Southern blotting. Current Protocols in Immunology 10.6.110.6.13. (doi:0.1002/0471142735.im1006as06)

Chambon P 1996 A decade of molecular biology of retinoic acid receptors. FASEB Journal 10 940-954.

Choudhary R, Palm-Leis A, Scott RC III, Guleria RS, Rachut E, Baker KM \& Pan J 2008a All-trans retinoic acid prevents development of cardiac remodeling in aortic banded rats by inhibiting the reninangiotensin system. American Journal of Physiology. Heart and Circulatory Physiology 294 H633-H644. (doi:10.1152/ajpheart.01301. 2007)

Choudhary R, Baker KM \& Pan J 2008b All-trans retinoic acid prevents angiotensin II- and mechanical stretch-induced reactive oxygen species generation and cardiomyocyte apoptosis. Journal of Cellular Physiology 215 172-181. (doi:10.1002/jcp.21297)

Earp HS, Huckle WR, Dawson TL, Li X, Graves LM \& Dy R 1995 Angiotensin II activates at least two tyrosine kinases in rat liver epithelial cells. Separation of the major calcium-regulated tyrosine kinase from p125FAK. Journal of Biological Chemistry 270 28440-28447. (doi:10.1074/jbc.270.47.28440)

Escobar E, Rodríguez-Reyna TS, Arrieta O \& Sotelo J 2004 Angiotensin II, cell proliferation and angiogenesis regulator: biologic and therapeutic implications in cancer. Current Vascular Pharmacology 2 385-399. (doi:10.2174/1570161043385556)

Gamble MV, Shang E, Piantedosi Zott R, Mertz JR, Wolgemuth DJ \& Blaner WS 1999 Biochemical properties, tissue expression and gene structure of a short chain dehydrogenase/reductase able to catalyze cis-retinol oxidation. Journal of Lipid Research $\mathbf{4 0}$ 2279-2292.

Ganceviciene R \& Zouboulis CC 2007 Isotretinoin: state of the art treatment for acne vulgaris. Expert Review of Dermatology 2 693-706. (doi:10.1586/17469872.2.6.693)

Grynkiewicz G, Poenie M \& Tsien RY 1985 A new generation of $\mathrm{Ca}^{2+}$ indicators with greatly improved fluorescence properties. Journal of Biological Chemistry 260 3440-3450.

Huckle WR, Prokop CA, Dy RC, Herman B \& Earp S 1990 Angiotensin II stimulates protein-tyrosine phosphorylation in a calciumdependent manner. Molecular and Cellular Biology 10 6290-6298. (doi:10.1128/MCB.10.12.6290)

Huckle WR, Dy RC \& Earp HS 1992 Calcium-dependent increase in tyrosine kinase activity stimulated by angiotensin II. PNAS $\mathbf{8 9}$ 8837-8841. (doi:10.1073/pnas.89.18.8837)

Kim Y-M, Sharma RP \& Li JK 1994 Characterization of heterologously expressed recombinant retinoic acid receptors with natural or synthetic retinoids. Journal of Biochemical Toxicology 9 225-234. (doi:10.1002/jbt.2570090502)

Kim MY, Baik SK, Park DH, Jang YO, Suk KT, Yea CJ, Lee IY, Kim JW, Kim HS, Kwon SO et al. 2008 Angiotensin receptor blockers are superior to angiotensin-converting enzyme inhibitors in the suppression of hepatic fibrosis in a bile duct-ligated rat model. Journal of Gastroenterology 43 889-896. (doi:10.1007/s00535-0082239-9)

Krskova-Tybitanclova K, Macejova D, Brtko J, Baculikova M, Krizanova O \& Zorad S 2008 Short term 13-cis-retinoic acid 
treatment at therapeutic doses elevates expression of leptin, GLUT4, PPARgamma and aP2 in rat adipose tissue. Journal of Physiology and Pharmacology 59 731-743.

Landthaler M, Kummermehr J, Wagner A \& Plewig G 1980 Inhibitory effects of 13-cis-retinoic acid on human sebaceous glands. Archives of Dermatological Research 269 297-309. (doi:10.1007/ BF00406424)

Leung PS 2004 The peptide hormone angiotensin II: its new functions in tissues and organs. Current Protein E Peptide Science 5 267-273. (doi:10.2174/1389203043379693)

Levin AA 1995 Receptors as tools for understanding the toxicity of retinoids. Toxicology Letters 82-83 91-97. (doi:10.1016/03784274(95)03546-X)

Li X \& Earp HS 1997 Paxillin is tyrosine-phosphorylated by and preferentially associates with the calcium-dependent tyrosine kinase in rat liver epithelial cells. Journal of Biological Chemistry $\mathbf{2 7 2}$ 14341-14348. (doi:10.1074/jbc.272.22.14341)

Li X, Yu H, Graves LM \& Earp HS 1997 Protein kinase C and protein kinase A inhibit calcium-dependent but not stress-dependent c-Jun N-terminal kinase activation in rat liver epithelial cells. Journal of Biological Chemistry 272 14996-15002. (doi:10.1074/jbc.272.23. 14996)

Li X, Lee JW, Graves LM \& Earp HS 1998 Angiotensin II stimulates ERK via two pathways in epithelial cells: protein kinase C suppresses a G-protein coupled receptor-EGF receptor transactivation pathway. EMBO Journal 17 2574-2583. (doi:10.1093/emboj/17.9.2574)

Lin HS, Leong WW, Yang JA, Lee P, Chan SY \& Ho PC 2007 Biopharmaceutics of 13-cis-retinoic acid (isotretinoin) formulated with modified beta-cyclodextrins. International Journal of Pharmaceutics 341 238-245. (doi:10.1016/j.ijpharm.2007.03.050)

Lu L, Yao T, Zhu YZ, Huang GY, Cao YX \& Zhu YC 2003 Chronic all-trans retinoic acid treatment prevents medial thickening of intramyocardial and intrarenal arteries in spontaneously hypertensive rats. American Journal of Physiology. Heart and Circulatory Physiology 285 H1370-H1377. (doi:10.1152/ajpheart.00260.2003)

Macejova D, Krizanova O \& Brtko J 2009 Different mRNA expression profiling of nuclear retinoic, thyroid, estrogen and PPAR $\gamma$ receptors, their coregulators and selected genes in rat liver and spleen in response to short-term in vivo administration of 13-cis retinoic acid. Toxicology Letters 184 114-120. (doi:10.1016/j.toxlet. 2008.10.031)

Maier LS 2008 Vitamin A for the heart: progress for cardiac hypertrophy regression? American Journal of Physiology. Heart and Circulatory Physiology 204 H588-H590. (doi:10.1152/ajpheart.00002. 2008)

Mangelsdorf DJ, Umesono K \& Evans RM 1994 The retinoid receptors. In The Retinoids, Biology, Chemistry, and Medicine, 2nd edn, pp 319-350. Eds MB Sporn, AB Roberts \& DS Goodman. New York: Raven Press.

Manolescu DC, Sima A \& Bhat PV 2010 All-trans retinoic acid lowers serum retinol-binding protein 4 concentrations and increases insulin sensitivity in diabetic mice. Journal of Nutrition 140 311-316. (doi:10.3945/jn.109.115147)

Mark M, Ghyselinck NB \& Chambon P 2006 Function of retinoid nuclear receptors: lessons from genetic and pharmacological dissections of the retinoic acid signaling pathway during mouse embryogenesis. Annual Review of Pharmacology and Toxicology 46 451-480. (doi:10.1146/annurev.pharmtox.46.120604.141156)

McCune BK \& Earp HS 1989 The epidermal growth factor receptor tyrosine kinase in liver epithelial cells. The effect of liganddependent changes in cellular location. Journal of Biological Chemistry 264 15501-15507.

Morath C, Ratzlaff K, Dechow C, Schwenger V, Schaier M, Zeier B, Peters J, Tsukada M, Zouboulis CC, Waldherr R et al. 2009 Chronic low-dose isotretinoin treatment limits renal damage in subtotally nephrectomized rats. Journal of Molecular Medicine 87 53-64. (doi:10.1007/s00109-008-0404-5)
Muindi JR, Roth MD, Wise RA, Connett JE, O'Connor GT, Ramsdell JW, Schluger NW, Romkes M, Branch RA, Sciurba FC et al. 2008 Pharmacokinetics and metabolism of all-trans- and 13-cis-retinoic acid in pulmonary emphysema patients. Journal of Clinical Pharmacology 48 96-107. (doi:10.1177/0091270007309701)

Mulholland CA \& Benford DJ 2007 What is known about the safety of multivitamin-multimineral supplements for the generally healthy population? Theoretical basis for harm American Journal of Clinical Nutrition 85 318S-322S.

Nickenig G 2002 Central role of the AT(1)-receptor in atherosclerosis. Journal of Human Hypertension 16 S26-S33. (doi:10.1038/sj.jhh. 1001436)

Numaguchi Y \& Murohara T 2009 RAAS and angiogenesis. Nippon Rinsho 67 723-728.

Ozawa Y, Kurihara T, Tsubota K \& Okano H 2011 Regulation of posttranscriptional modification as a possible therapeutic approach for retinal neuroprotection. Journal of Ophthalmology 2011506137. (doi:10.1155/2011/506137)

Paiva SA, Matsubara LS, Matsubara BB, Minicucci MF, Azevedo PS, Campana AO \& Zornoff LA 2005 Retinoic acid supplementation attenuates ventricular remodeling after myocardial infarction in rats. Journal of Nutrition 135 2326-2328.

Palm-Leis A, Singh US, Herbelin BS, Olsovsky GD, Baker KM \& Pan J 2004 Mitogen-activated protein kinases and mitogen-activated protein kinase phosphatases mediate the inhibitory effects of alltrans retinoic acid on the hypertrophic growth of cardiomyocytes. Journal of Biological Chemistry 279 54905-54917. (doi:10.1074/jbc. M407383200)

Park SH, Woo CH, Kim JH, Lee JH, Yang IS, Park KM \& Han HJ 2002 High glucose down-regulates angiotensin II binding via the PKC-MAPK-CPLA2 signal cascade in renal proximal tubule cells. Kidney International 61 913-925. (doi:10.1046/j.1523-1755.2002. 00204.x)

Piattellia B, Fioronic M, Santinellid A \& Rubinie C 1999 bcl-2 expression and apoptotic bodies in 13-cis-retinoic acid (isotretinoin)-topically treated oral leukoplakia: a pilot study. Oral Oncology 35 314-320. (doi:10.1016/S1368-8375(98)00095-5)

Ratziu V \& Zelber-Sagi S 2009 Pharmacologic therapy of non-alcoholic steatohepatitis. Clinics in Liver Disease 13 667-688. (doi:10.1016/j. cld.2009.07.001)

Rigopoulos D, Larios G \& Katsambas AD 2010 The role of isotretinoin in acne therapy: why not as first-line therapy? Facts and controversies Clinics in Dermatology 28 24-30. (doi:10.1016/j. clindermatol.2009.03.005)

Rosenfeld MG \& Glass CK 2001 Coregulator codes of transcriptional regulation by nuclear receptors. Journal of Biological Chemistry 276 36865-36868. (doi:10.1074/jbc.R100041200)

Schug TT, Berry DC, Toshkov IA, Cheng L, Nikitin AY \& Noy N 2008 Overcoming retinoic acid-resistance of mammary carcinomas by diverting retinoic acid from PPARbeta/delta to RAR. PNAS 105 7546-7551. (doi:10.1073/pnas.0709981105)

Siitonen T, Timonen T, Juvonen E, Terävä V, Kutila A, Honkanen T, Mikkola M, Hallman H, Kauppila M, Nyländen P et al. 2007 Valproic acid combined with 13-cis retinoic acid and 1,25-dihydroxyvitamin $\mathrm{D}_{3}$ in the treatment of patients with myelodysplastic syndromes. Haematologica 92 1119-1122. (doi:10.3324/haematol.11262)

Skultetyova D, Filipova S, Riecansky I \& Skultety J 2007 The role of angiotensin type 1 receptor in inflammation and endothelial dysfunction. Recent Patents on Cardiovascular Drug Discovery 2 23-27. (doi:10.2174/157489007779606130)

Sookoian S, Fernández MA \& Castaño G 2005 Effects of six months losartan administration on liver fibrosis in chronic hepatitis C patients: a pilot study. World Journal of Gastroenterology $117560-7563$

Sugawara A, Takeuchi K, Uruno A, Kudo M, Sato K \& Ito S 2003 Effects of mitogen-activated protein kinase pathway and co-activator CREP-binding protein on peroxisome proliferator-activated 
receptor-gamma-mediated transcription suppression of angiotensin II type 1 receptor gene. Hypertension Research 26 623-628. (doi:10. 1291/hypres.26.623)

Swillens S 1992 How to estimate the total receptor concentration when the specific radioactivity of the ligand is unknown. Trends in Pharmacological Sciences 13 430-434. (doi:10.1016/01656147(92)90139-W)

Takeda K, Ichiki T, Funakoshi Y, Ito K \& Takeshita A 2000 Downregulation of angiotensin II type 1 receptor by all-trans retinoic acid in vascular smooth muscle cells. Hypertension $\mathbf{3 5}$ 297-302. (doi:10.1161/01.HYP.35.1.297)

Thekkumkara TJ \& Linas SL 2003 Evidence for involvement of 3'untranslated region in determining angiotensin II receptor coupling specificity to G-protein. Biochemical Journal 370 631-639. (doi:10.1042/BJ20020960)

Thekkumkara TJ, Du J, Dostal DE, Motel TJ, Thomas WG \& Baker KM 1995 Stable expression of a functional rat angiotensin II (AT1A) receptor in CHO-K1 cells: rapid desensitization by angiotensin II. Molecular and Cellular Biochemistry 146 79-89. (doi:10.1007/ BF00926885)

Thomas BE \& Thekkumkara TJ 2004 Glucose mediates transcriptional repression of the human angiotensin type-1 receptor gene: role for a novel cis-acting element. Molecular Biology of the Cell 15 4347-4355. (doi:10.1091/mbc.E04-03-0203)

Trichard L, Fattal E, Besnard M \& Bochot A 2007 Alpha-cyclodextrin/oil beads as a new carrier for improving the oral bioavailability of lipophilic drugs. Journal of Controlled Release 122 47-53. (doi:10. 1016/j.jconrel.2007.06.004)

Tsao MS, Smith JD, Nelson KG \& Grisham JW 1984 A diploid epithelial cell line from normal adult rat liver with phenotypic properties of 'oval' cells. Experimental Cell Research 154 38-52. (doi:10.1016/00144827(84)90666-9)

Tsao MS, Earp HS \& Grisham JW 1986 The effects of epidermal growth factor and the state of confluence on enzymatic activities of cultured rat liver epithelial cells. Journal of Cellular Physiology 126 167-173. (doi:10.1002/jcp.1041260204)

Wakui H, Tamura K, Matsuda M, Bai Y, Dejima T, Shigenaga A, Masuda S, Azuma K, Maeda A, Hirose T et al. 2010 Intrarenal suppression of angiotensin II type 1 receptor binding molecule in angiotensin II-infused mice. American Journal of Physiology. Renal Physiology 299 F991-F1003. (doi:10.1152/ajprenal.00738.2009)
Wang HJ, Zhu YC \& Yao T 2002 Effects of all-trans retinoic acid on angiotensin II-induced myocyte hypertrophy. Journal of Applied Physiology 92 2162-2168. (doi:10.1152/japplphysiol.01192.2001)

Wang W, Zhang X, Zheng J \& Yang J 2010 High glucose stimulates adipogenic and inhibits osteogenic differentiation in MG-63 cells through cAMP/protein kinase A/extracellular signal-regulated kinase pathway. Molecular and Cellular Biochemistry 338 115-122. (doi:10.1007/s11010-009-0344-6)

Wassmann S \& Nickenig G 2006 Pathophysiological regulation of the AT1-receptor and implications for vascular disease. Journal of Hypertension 24 S15-S21. (doi:10.1097/01.hjh.0000220402. 53869.72)

Wei Y, Clark SE \& Morris EM 2008 Angiotensin II-induced non-alcoholic fatty liver disease is mediated by oxidative stress in transgenic TG(mRen2)27(Ren2) rats. Journal of Hepatology 49 417-428. (doi:10.1016/j.jhep.2008.03.018)

Wu JM, Garami M, Cheng T \& Gardner DG 1996 1,25(OH $)_{2}$ Vitamin $\mathrm{D}_{3}$ and retinoic acid antagonize endothelin-stimulated hypertrophy of neonatal rat cardiac myocytes. Journal of Clinical Investigation 97 1577-1588. (doi:10.1172/JCI118582)

Yen A, Roberson MS, Varvayanis S \& Lee AT 1998 Retinoic acid induced mitogen-activated protein (MAP)/extracellular signalregulated kinase (ERK) kinase-dependent MAP kinase activation needed to elicit HL-60 cell differentiation and growth arrest. Cancer Research 58 3163-3172.

Yoshiji H, Noguchi R, Ikenaka Y, Namisaki T, Kitade M, Kaji K, Shirai Y, Yoshii J, Yanase K, Yamazaki M et al. 2009 Losartan, an angiotensin-II type 1 receptor blocker, attenuates the liver fibrosis development of non-alcoholic steatohepatitis in the rat. BMC Research Note 270. (doi:10.1186/1756-0500-2-70)

Zhang C \& Duvic M 2003 Retinoids: therapeutic applications and mechanisms of action in cutaneous T-cell lymphoma. Dermatologic Therapy 16 322-330. (doi:10.1111/j.1396-0296.2003.01644.x)

Received in final form 7 November 2011

Accepted 15 December 2011

Made available online as an Accepted Preprint 16 December 2011 